\title{
Nanotechnology based approaches for detection and delivery of microRNA in healthcare and crop protection
}

\author{
Vrantika Chaudhary, Sumit Jangra and Neelam R. Yadav*
}

\begin{abstract}
Nanobiotechnology has the potential to revolutionize diverse sectors including medicine, agriculture, food, textile and pharmaceuticals. Disease diagnostics, therapeutics and crop protection strategies are fast emerging using nanomaterials preferably nanobiomaterials. It has potential for development of novel nanobiomolecules which offer several advantages over conventional treatment methods. RNA nanoparticles with many unique features are promising candidates in disease treatment. The miRNAs are involved in many biochemical and developmental pathways and their regulation in plants and animals. These appear to be a powerful tool for controlling various pathological diseases in human, plants and animals, however there are challenges associated with miRNA based nanotechnology. Several advancements made in the field of miRNA therapeutics make it an attractive approach, but a lot more has to be explored in nanotechnology assisted miRNA therapy. The miRNA based technologies can be employed for detection and combating crop diseases as well. Despite these potential advantages, nanobiotechnology applications in the agricultural sector are still in its infancy and have not yet made its mark in comparison with healthcare sector. The review provides a platform to discuss nature, role and use of miRNAs in nanobiotechnology applications.
\end{abstract}

Keywords: miRNA, Nanotechnology, Nanomaterials, Disease control, miRNA detection and delivery, Therapeutics, Plants, Animals, Humans

\section{Background}

Nanotechnology, an emerging field of research encompassing the creation and usage of materials at nano scale, at the interface of physical and biological sciences using either top-down approaches or bottom-up assembly. In the biological domain a huge number of well-organised structures and nanomachines made up of macromolecules have been designed to carry out various biological functions. Their fascinating make-up have encouraged many biometric designs due to unique characteristics of DNA, RNA and proteins at nano scale, these can be a platform for the development of nano structures and devices. The idea was pioneered 30 years ago by developing nanostructures using DNA, leading to explosion of information in the well-recognised field of DNA

*Correspondence: nryadav58@gmail.com

Department of Molecular Biology, Biotechnology and Bioinformatics, CCS Haryana Agricultural University, Hisar 125004, India nanotechnology [1]. Nowadays, RNA molecules have gained interest because of their amazing diversity with respect to structure and function. The packaging RNA (pRNA) molecule can be linked with several therapeutic aids including aptamers, ribozymes, siRNA (small interfering RNA) and miRNA [2]. These outcomes have built a way for RNA nanotechnology to develop novel therapeutic methods for treatment and diagnosis of various type of tumours, viral infections and genetic diseases in humans, animals and plants.

The miRNA is endogenous non-coding RNA, which recently has been found to play a key role in regulatory functions responsible for gene expression in all the organisms. Typically, miRNA is $18-23$ nucleotides in length and plays an important role in post transcriptional regulation. These are active and dynamic in cytoplasm, in spite of the fact that their synthesis and transcription takes place in the nucleus. The miRNA profile is changed in diseased state making miRNAs a great target 
for drug therapy through RNA nanotechnology. Restoration of down-regulated miRNA or restraint of overexpressed miRNA to return miRNA to its ordinary state is the premise of miRNA based disease control which can be additionally investigated to control and manage other various cellular functions also. The therapeutic potential of miRNAs was first realized with the discovery that downregulation of miR-15 and miR-16 is associated with development of B cell leukaemia [3]. Since then these small non-coding RNA have drawn attention not only in biomedical research and drug development but in crop protection also as the expression level of key genes can be controlled by manipulation of cellular miRNAs. This review focuses on current knowledge on miRNA based detection and treatment of various disease using RNA nanotechnology. It also highlights the future prospects of various strategies of RNA nanotechnology to be applicable in plant science together with major obstacles that need to be overcome for successful application.

\section{Biogenesis and mechanism of action of miRNA}

The biogenesis and maturation of miRNA requires different strides which includes nuclear processing, nuclear export and cytoplasmic processing. RNA polymerase II first transcribes the miRNA genes leading to the formation of long primary transcript having a hairpin structure [4-6]. The process of miRNA maturation is initiated by Drosha, cleaving the local stem-loop structure, releasing a $~ 65$ nucleotides long hairpin structure (pre-miRNA) $[7,8]$. Pre-miRNA is translocated to cytoplasm immediately after Drosha processing, where maturation takes place. A transport complex is formed by protein exportin 5 (EXP5), RAN-GTP, a GTP binding nuclear protein and pre-miRNA [9-13]. Upon export to the cytoplasm, pre-miRNA is cleaved by Dicer near the terminal loop, liberating a small duplex [14-16]. The RNA-induced silencing complex (RISC) is formed by loading of small RNA duplexes generated by Dicer onto AGO (Argonaute) protein [17-22]. After loading of miRNA duplex, the pre-RISC rapidly removes the passenger strand and generates mature RISC. This binds to the 3 -untranslated region (UTR) of the target mRNA based on a partial miRNA-mRNA complementarity leading to translational inhibition and/or degradation of the target mRNA.

Plant miRNAs (highly variable in length) are generally transcribed by RNA pol II in a way similar to animals [23-25]. However, unlike animals, processing of plant pre-miRNA occurs in nucleus and homologues of Drosha and DGCR8 are not reported. Most of the processing is done by DICER-LIKE 1 protein by sequential cleavage. DCL 1 (DICER-LIKE 1) interacts with DAWDLE (DDL), an RNA binding protein and stabilizes premiRNA nuclear foci called D-bodies (dicing bodies).
A complex is formed by SERRATE (SE), a zinc figure protein, HYPONASTIC LEAVES 1 (HYL1) a dsRNA binding protein and nuclear cap-binding complex and process pre-miRNA [26-28]. After processing, HUA ENHANCER1 (HEN1) the $3^{\prime}$ end of the miRNA passenger strand is methylated at $2^{\prime}-\mathrm{O}$, which blocks uridylation by HEN 1 SUPPRESSOR [26, 28] and decomposition of miRNAs by SMALL-RNA DEGRADING NUCLEASE 1 , a $3^{\prime}-5^{\prime}$ exoribonuclease [28-30]. After processing, HASTY (HST) export mature miRNA to cytoplasm [26].

\section{Expression pattern of miRNA in diseased state}

MiRNAs are involved in various biological processes such as cell growth and development, biogenesis, signal transduction and apoptosis. MiRNA genes are frequently subjected to genetic alterations as they are located in fragile genomic regions. The epigenetic changes can bring about varied miRNA expression prompting to over expression or down regulation of miRNA leading to various diseases like cardiac, diabetes, neurological and many more. MiR145 is differentially expressed in various types of cancers like colon, breast, lung and prostate [31-35].

A large number of miRNAs have been reported in plants, which are evolutionary conserved and regulate several biological processes. These are also found to be associated with various bacterial, fungal and viral diseases. These miRNAs are differentially expressed in growth and development as well in response to biotic and abiotic stress. The miR156 and miR159 are dominant families which are associated with pathogen response in plants and can be targeted for controlling serval bacterial, fungal and viral diseases in plants. These miRNA families may provide an excellent opportunity for engineering disease resistance for crop protection. For example, differential expression of miRNA has also been observed in diseased plants. Twelve miRNAs (miR156, miR159, miR160, miR164, miR166, miR168, miR172, miR319, miR398, miR408, miR1448 and miR1450) were found upregulated in stem bark of $P$. trichocarpa when infected with stem canker pathogen [36]. Many highly conserved miRNAs (miR156, miR159, miR160, miR162, miR166, miR167, miR169, miR172, miR319 and miR396) were downregulated upon infection with Verticillium dahlia in Eggplant [37]. Gao et al. found that in the plants infected with HCRV (Hibiscus chlorotic ringspot virus), the level of four conserved miRNAs (miR171, miR168, miR167 and miR165) increased with the increase in sulphite oxidase (SO) level [38]. Wu et al. for the first time showed that miR811 and miR829 confers a high degree of resistance to Exserohilum turcicum in maize. They also found that miR811, miR829, miR845 and miR408 were differentially expressed in infected plants [39]. Aberu et al. reported that the expression of four miRNAs (miR156, 
miR162, miR398 and miR408) involved in proteasomal degradation in papaya when infected with Papaya meleira virus was increased in response to very low levels of $\mathrm{PMeV}$ titre and decreased as the viral titre increases [40]. Twenty miRNAs (osa-miR812j, osa-miR5072, osa-miR444a-5p, osa-miR396c-3p, osa-miR1870-5p, osa-miR1863b.2, osa-miR172d-5p, osa-miR171c-3p, osa-miR167a-5p, osa-miR166d-5p, osa-miR159b, osamiR156-3p, osa-miR15a, osa-miR1432-5p, osa-miR1432p, osa-miR1429-5p, osa-miR1432-3p, osa-miR1429-5p, osa-miR1425-3p, osa-miR1423-5p and osa-miR1320-5p) are upregulated upon infection with rice stripe virus in susceptible plants [41]. In Ziziphus jujube, $12 \mathrm{miR}$ NAs were upregulated two-fold including miR156a, miR156b, miR156c, miR156d, miR156e, miR156 h, miR159e, miR319a, miR395a, miR395b, zju-miRn23 and zju-miRn24. Ten miRNA were down regulated twofold including miR159a, miR172, miR2111, miR2950, miR399, miR477, miR858b, zju-miRn2, zju-miRn8 and zju-miRn16 in response to Witches'-Broom phytoplasma infection [42]. A decrease in slmiR4828 and slmiR5300 was observed in Motelle plant when infected with $F$. Oxysporum [43]. This differential expression of miRNAs in humans, animals and plants has been analysed for early detection of diseases as discussed in Table 1.

Interplay of TFs with miRNA is well-known. For example in wheat, interaction between miR164 and a novel transcription factor NAC21/22 is said to be involved with resistance against Puccinia [44]. In Populus, TCrich repeats, MBS and W1-box are three most dominating cis-elements present in fungus responsive miRNA accounting for $92.7,85.4$ and $82.9 \%$ of 41 fungi-responsive miRNA molecules [36]. WRKY transcription factors interact with Md-miR156ab and Md-miR395 to induce resistance against leaf spot disease in apple [45]. NF-YA transcription factor and miR169 are involved in R. solanacearum pathogenicity in Arabidopsis [46].

\section{Nanotechnology for miRNA detection}

MiRNAs are key governors of altered gene expression under many pathological conditions in plants, animals and humans, and are characterized by altered miRNA levels. Therefore, precise and sensitive assessment of miRNA can lead to early and correct disease diagnosis and make these small noncoding RNA transcripts a valuable biomarker [85]. Conventionally, miRNA detection is based on real-time polymerase chain reaction (qRT-PCR) and microarrays. These techniques are error prone, undergo cross hybridization and need legitimate and valid internal control because miRNA are short sequences making designing of probes and primers difficult [86, 87]. Aiming at overcoming some limitations of conventional quantification techniques, nanotechnology is right choice making sensitive and stringent alternatives for miRNA sensing.

\section{Nanoparticle based miRNA detection}

Gold nanoparticles promise a viable and sensitive detection technology as their optical properties can easily be tuned and can be surface functionalized using a variety of well characterized chemical moieties that is thiols, disulphides and amines [88]. Gold nanoparticles-decorated graphene field-effect transistor (FET) biosensor is highly sensitive, selective and can be used for label-free detection of miRNA. It is a potential technique for diagnosis of genetic diseases [89]. Gold nanoparticle coated magnetic microbeads are used as an immobilization matrix for higher loading density of hairpin-structured probes. Ferrocene (Fc)-capped gold nanoparticle/streptavidin conjugates, amplified electrochemical assay of miRNA has been performed for the detection of miRNA-182 from serum samples of glioma patients [90]. A new class of intracellular nanoprobe, termed AuNP loaded split DNAzyme-probe was developed to sense miRNA in living cells. In the absence of target miRNA, the split DNAzymes form an inactive DNAzyme motif with their substrate through partial pairing at the end of each strand and the fluorescence is quenched. Inside the cells, the target miRNA binds with both of the two halves of split DNAzymes forming the active secondary structure in the catalytic cores which can cleave the substrates resulting in the rupture of the substrate and recovery of fluorescence [91]. A dual-mode electronic biosensor was developed for miRNA-21 detection based on gold nanoparticle-decorated MoS2 nano-sheet which may prove to be potential candidate in biosensing field from nucleic acid to protein detection [92]. A sensor for the detection of specific miRNA sequences was developed based on graphene quantum dots (GQDs) and ssDNA-UCNP@ $\mathrm{SiO}_{2}$ [93]. Carbonaceous nanomaterials such as nanosized graphene oxide and carbon nanoparticles have also been used in miRNA detection which is based on their fluorescence quenching properties [85]. The identification and detection of miRNAs has profound implications in cancer therapy [94] and nanoparticles can assist in development of novel disease treatment strategies.

\section{Nanopore based miRNA detection}

Nanopore provides a sore single molecule platform for digging into a large variety of life science troubles [95-97]. Nanopore sequencing applications have gained momentum and the technology has become cheaper. Nevertheless, nanopores have the capacity to detect epigenetic changes in a DNA sequence. Nanopore can detect the position and conformation of a single molecule with high specificity that is present in pore lumen. 
Table 1 Up regulation and downregulation of various miRNA in diseased state

\begin{tabular}{|c|c|c|c|c|c|c|}
\hline Micro RNA & \multicolumn{2}{|c|}{ Up/down regulated } & \multicolumn{2}{|c|}{ Disease } & \multicolumn{2}{|c|}{ References } \\
\hline \multicolumn{7}{|l|}{ Humans } \\
\hline $\begin{array}{l}\text { miR-660-3p, miR-665, miR-1285-3p and miR-4491, miR-21, miR-29b, miR-34, } \\
\text { miR-122, miR-129, miR-142-3p, miR-199, miR-210, miR-211, miR-212, miR- } \\
\text { 379, miR-423-5p and miR-503 }\end{array}$ & \multicolumn{2}{|l|}{ Up } & \multicolumn{2}{|c|}{ Chronic heart failure } & \multicolumn{2}{|c|}{$[47-49]$} \\
\hline $\begin{array}{l}\text { miR-221-30, miR-487b-3p, miR-4288, miR-30, miR-107, miR-125b, miR-126, } \\
\text { miR-139, miR-142-5p, miR-182, miR-497 and miR-526 }\end{array}$ & \multicolumn{2}{|l|}{ Down } & \multicolumn{2}{|c|}{ Chronic heart failure } & \multicolumn{2}{|c|}{$[47-49]$} \\
\hline miR-133 and miR-208a & \multicolumn{2}{|l|}{ Up } & \multicolumn{2}{|c|}{ Coronary artery disease } & \multicolumn{2}{|l|}{ [50] } \\
\hline miR-126, miR-17, miR-92a, miR-145 and miR-155 & \multicolumn{2}{|l|}{ Down } & \multicolumn{2}{|c|}{ Coronary artery disease } & \multicolumn{2}{|l|}{ [50] } \\
\hline $\begin{array}{l}\text { miR-24, miR-21, miR-20b, miR-15a, miR-126, miR-191, miR-197, miR-223, } \\
\text { miR-320, miR-486, miR-150, miR-29b, miR-206 and miR-133a }\end{array}$ & \multicolumn{2}{|l|}{ Down } & \multicolumn{2}{|c|}{ Type-II diabetes } & \multicolumn{2}{|c|}{$[51,52]$} \\
\hline $\begin{array}{l}\text { miR-28-3p, miR-9, miR-29a, miR-30d, miR34a, miR-124a, miR-146a and } \\
\text { miR375 }\end{array}$ & \multicolumn{2}{|l|}{ Up } & \multicolumn{2}{|c|}{ Type-II diabetes } & \multicolumn{2}{|c|}{$[51,53]$} \\
\hline miR-150, miR-27a, miR-192, miR-320a and miR-375 & \multicolumn{2}{|l|}{ Up } & \multicolumn{2}{|c|}{ Type-II diabetes } & \multicolumn{2}{|l|}{ [54] } \\
\hline $\begin{array}{l}\text { miR-152, miR-30a-5p, miR-181a, miR-24, miR-148a, miR-210, miR-27a, miR- } \\
\text { 29a, miR-26a, miR-27b, miR-25 and miR-200a }\end{array}$ & \multicolumn{2}{|l|}{ Up } & \multicolumn{2}{|c|}{ Type-I diabetes } & \multicolumn{2}{|l|}{$[55]$} \\
\hline miR-21a, miR-93, miR-31, miR-9, miR-34a, miR-155, miR-181a and miR-199a & \multicolumn{2}{|l|}{ Down } & Type-1 & diabetes & {$[56,5]$} & \\
\hline miR-29a, miR-122, miR-132, & Down & & Gestati & ional diabetes mellitus & {$[58]$} & \\
\hline miR-29aand miR-92a & Up & & Colore & ctal cancer & [59] & \\
\hline mir-009-1, mir-155, mir-213 and mir-102 & Up & & Breast & cancer & [60] & \\
\hline $\begin{array}{l}\text { mir-010b, mir-021, mir-034, mir-123, mir-125a, mir125b-1, mir-140-as, mir- } \\
\text { 145, mir-194 and mir-204 }\end{array}$ & Down & & Breast & cancer & [60] & \\
\hline miR-200a, miR-200b, miR-200c, miR-141, miR-205, miR-21 and miR-182 & Up & & Ovariar & n cancer & {$[61]$} & \\
\hline $\begin{array}{l}\text { mir-124a, mir-211, mir-216, mir-302c, mir-145, mir-29c, mir-181a, mir-302, } \\
\text { let-7c, mir-98, mir-19b, mir-29b, mir-18a, mir-154, mir-19a, mir-153, mir- } \\
\text { 144, mir-222, mir-302a, mir-204, mir-101-1, mir-214, mir-34c, mir-374, } \\
\text { mir-195, mir-215, mir-28, mir-29a, mir-133b, mir-299-5p, mir-7-2, let-7f, } \\
\text { mir-139, mir-193, mir-323, mir-134, mir-370, let-7d, mir-100, mir-101, mir- } \\
\text { 105, mir-125a, mir-125b-1, mir-126, mir-133a, mir-137, mir-140, mir-143, } \\
\text { mir-147, mir-199a, mir-199b, mir-224, mir-302b, mir-9 and mir-99a }\end{array}$ & Down & & Ovaria & n cancer & {$[61]$} & \\
\hline $\begin{array}{l}\text { miR-20, miR-21, miR-99a, miR-141, miR-182, miR-198, let-7a, miR-148a, } \\
\text { miR-200c, miR-375, miR-96, miR-141, miR-145, miR-155, miR-34, miR-34c, } \\
\text { miR-187, miR-221 and miR-224 }\end{array}$ & Up & & Prostat & e cancer & {$[62-6$} & \\
\hline $\begin{array}{l}\text { miR-145, miR-155, miR-143, miR-223, miR-149, miR-181b, miR-205, let-7a } \\
\text { and miR-182 }\end{array}$ & Down & & Prostat & e cancer & {$[62-6$} & \\
\hline miR-30e, miR-181b, miR-34a, miR-346 and miR-7 & Up & & Schizo & phrenia & [67] & \\
\hline $\begin{array}{l}\text { miR-151a-3p, miR-181b-5p, miR-320a, miR-328, miR-433, miR-489, miR-572 } \\
\text { and miR-663a }\end{array}$ & Down & & Autism & & [68] & \\
\hline $\begin{array}{l}\text { miR-101-3p, miR-106b-5p, miR-19b-3p, miR-195-5p, miR-130a-3p and miR- } \\
27 a-3 p\end{array}$ & Up & & Autism & & [68] & \\
\hline $\begin{array}{l}\text { miR-98-5p, miR-885-5p, miR-483-3p, miR-342-3p, miR-191-5p and miR-let- } \\
\text { 7d-5p }\end{array}$ & Down & & Alzheir & ner's & [69] & \\
\hline miR-194-5p, miR-301a-3p, miR-30b-5p, miR-342-5p and miR-4446-3p & Down & & Drug re & esistant epilepsy & [70] & \\
\hline Micro RNA & Animal & Up/down regu & ulated & Disease & & References \\
\hline Animals & & & & & & \\
\hline $\begin{array}{l}\text { bta-miR-15b, bta-miR-17-3p, bta-miR-16b, bta-miR-148a, bta-miR-26b, } \\
\text { bta-miR-101, bta-miR-29b, bta-miR-27b and bta-miR-215 }\end{array}$ & Cow & Up & & Bovine metritis & & [71] \\
\hline $\begin{array}{l}\text { bta-miR-148b, bta-miR-199a-3p, bta-miR-122, bta-miR-200b and bta-miR- } \\
\text { 10a }\end{array}$ & Cow & Down & & Bovine metritis & & [71] \\
\hline mir-19b & Pig & Down & & PPV infection & & [72] \\
\hline bta-mir-100 & Cow & Up & & S. uberis infection & & [73] \\
\hline $\begin{array}{l}\text { bta-mir-19b, bta-mir-19b-2, bta-mir-1271, bta-mir-100, bta-mir-301a, bta- } \\
\text { mir-32, Novel-14_7917 }\end{array}$ & Cattle & Down & & Paratuberculosis & & [74] \\
\hline bta-mir-6517, bta-mir-7857 & Cattle & Up & & Paratuberculosis & & [74] \\
\hline bta-miR-24-3p & Cattle & Up & & Mycoplasma bovis infec & ction & [75] \\
\hline bta-miR-92a, miR-92a & Cattle & Down & & Mycoplasma bovis infec & ction & [75] \\
\hline
\end{tabular}


Table 1 continued

\begin{tabular}{|c|c|c|c|c|}
\hline Micro RNA & Plant & Up/down regulated & Disease & Reference \\
\hline \multicolumn{5}{|l|}{ Plants } \\
\hline $\begin{array}{l}\text { vvi-miR395a-m, vvi-miR398b-c, vvimiR408, ccamiR408, } \\
\text { c31052, c141107, c141224 and c205570 }\end{array}$ & Grapevine & Up & Leaf roll associated virus-3 infection & [76] \\
\hline miR171 & Arabidopsis & Down & Viral infection & [77] \\
\hline $\begin{array}{l}\text { miR156, miR157, miR158, miR162, miR164, miR167 and } \\
\text { miR171 }\end{array}$ & Arabidopsis & Up & Turnip yellow mosaic virus & [78] \\
\hline miR393 & Arabidopsis & Up & P. syringae & [79] \\
\hline miR393 & Soybean & Up & P. sojae & {$[80]$} \\
\hline miR482, miR1448, miR1971 and miR2118 & Cotton & Down & Vetricillium & {$[81,82]$} \\
\hline miR156, miR159, miR164, miR168 & Wheat & Down & Erysiphe graminis f. sp. Tritici & [83] \\
\hline $\begin{array}{l}\text { miR156, miR159, miR164, miR168, miR169, miR172, } \\
\text { miR393, miR396, miR482, miR1448, Phe-SR3, Phe- } \\
\text { SR23, Phe-SR25 }\end{array}$ & Populus beijingensis & Up & Dothiorella gregaria & [84] \\
\hline miR156, miR162, miR398 and miR408 & Papaya & Up & Papaya meleria & [40] \\
\hline miR845 and miR811 & Maize & Up & Exserohilum turcicum & [39] \\
\hline $\begin{array}{l}\text { osa-miR812j, osa-miR5072, osa-miR444a-5p, osa- } \\
\text { miR396c-3p, osa-miR1870-5p, osa-miR1863b.2, } \\
\text { osa-miR172d-5p, osa-miR171c-3p, osa-miR167a-5p, } \\
\text { osa-miR166d-5p, osa-miR159b, osa-miR156-3p, } \\
\text { osa-miR15a, osa-miR1432-5p, osa-miR1432-p, osa- } \\
\text { miR1429-5p, osa-miR1432-3p, osa-miR1429-5p, osa- } \\
\text { miR1425-3p, osa-miR1423-5p and osa-miR1320-5p }\end{array}$ & Rice & Up & Rice stripe rust virus & [41] \\
\hline $\begin{array}{l}\text { miR156a, miR156156b, miR156c, miR156d, miR156e, } \\
\text { miR156 h, miR159e, miR319a, miR395a, miR395b, } \\
\text { zju-miRn23 and zju-miRn24 }\end{array}$ & Ziziphus jujube & Up & Witches'-Broom phytoplasma & [42] \\
\hline $\begin{array}{l}\text { miR159a, miR172, miR2111, miR2950, miR399, miR477, } \\
\text { miR858b, zju-miRn2, zju-miRn8 and zju-miRn16 }\end{array}$ & Ziziphus jujube & Down & Witches'-Broom phytoplasma & {$[42]$} \\
\hline slmiR4828 and slmiR5300 & Motelle & Down & F. oxysporum & {$[43]$} \\
\hline
\end{tabular}

By the particular conductance change in nanopore, one can electrically measure and elucidate single-molecule kinetic pathways in the target. In light of biotechnological applications, different nanopore sensors have been produced $[98,99]$. In the today's quickly advancing technology, development of nanopore based miRNA detectors is a novel exertion. A $3 \mathrm{~nm}$ synthetic probe was used for the first time to quantify the translocation of enriched miRNA that was hybridized to a probe [100]. They developed a nanopore based miRNA detector for lung cancer that produced signature electric signs using a programmable oligonucleotide probe for direct and label free identification of target miRNA in wavering surrounding. The key segment of the nanopore detector is the probe whose sequence is programmable and can be improved to accomplish high sensitivity and selectivity. Specific chemical modification can be employed to engineer the probe, so that simultaneous miRNA detection can be done using distinct probe $[97,98]$. This sensor can be utilized for the detection of miRNAs, nucleic acid fragments [101, 102], genetic alterations and pathogenic DNA/ RNAs. High throughput detection can be done by utilizing a newer membrane platform droplet interface bilayer
[103]. Sub-picomolar levels of miRNAs can be quantified using this technique [104] and nanopore-based miRNA detection techniques will be further improved and validated for disease control in coming future [105].

\section{MiRNA therapeutics}

Despite the fact that we have just barely started to pick up bits of knowledge into the full scope of biologic elements of miRNA, their inclusion in the onset and movement of diseases has created huge enthusiasm for its use in therapeutics. Mounting proofs recommend that miRNA-based treatments, either by restoring or repressing miRNAs expression and activity hold great promise in therapeutics. The unusual expression of miRNA in various diseases makes it a critically important focus for researcher to create more strategies to develop newer techniques for disease diagnostics and treatment. Biologists have understanding that several different miRNAs are upregulated upon infection with various diseases. Under this situation, antisense inhibitors of the overexpressed mature miRNA sequence can be used to hinder the overexpression as restorative technique. The miRNA expression can be reset to restore the normal cell 
functioning by providing mature miRNA exogenously. Presently, miRNA activity is regulated by two approaches (i) restoring miRNA function using synthetic double stranded miRNAs, (ii) inhibiting miRNA function using chemical modified anti-miR oligonucleotides [106].

\section{Restoring miRNA function}

The normal functionality of miRNA in the diseased conditions which caused downregulation of miRNA can be regained by two ways [107]. First by direct replacement miRNA equivalent to dicer products using synthetic mimics of the targeted mature miRNA. These engineered mimics are closely resembled siRNA and can be straightforwardly delivered into the cell cytoplasm for loading into RISC complex [108]. The other approach to restoring typical miRNA function is overexpression of specific miRNA utilizing vectors. Short hairpin RNA from polymerase II or III promoters has been expressed and processed by Dicer ahead of RNA loading into RISC [109].

\section{MiRNA inhibition}

When miRNA upregulation leads to disease symptoms, the miRNA inhibition therapy can be employed to regulate the expression. Most methods involve miRISC complex disruption. MiRNA inhibition can be done either by using miRNA sponges or antisense oligonucleotides called anti-miRs. In miRNA sponge, the function of a specific miRNA or miRNA family is blocked by transgenic overexpression of RNA molecule harbouring complementary sites to miRNA of interest [110]. Chemically modified anti-miR oligonucleotides are required for efficient silencing of dysregulated miRNA in vivo due to better binding affinity, biostability and pharmacokinetic properties. The chemical modifications includes phosphorothioates containing oligonucleotides [111], 2'-o methyl-(2'-O-Me) or 2'-O-methoxyethykoligonucleotides [112], locked nucleic acids (LNA) oligonucleotides [113], peptide nucleic acids [114], fluorine derivatives (FANA and $2^{\prime} \mathrm{F}$ ) and other modifications [115]. For improving the duplex melting temperature and enhancing nuclease resistance of antimiRs sugar modification is most commonly employed. Locked nucleic acids are found to have superior in vivo stability and target binding ability and show the highest affinity towards complementary RNA making use of miRNA as therapeutics a great consideration [116-118]. MiRNA represents a novel and attractive target in terms of scientific perspectives to manipulate body functions. A snapshot of present development status of miRNA based therapeutics is presented in Table 2.

\section{Challenges in miRNA based therapies}

With the advancement of RNA innovation, miRNA have drawn extraordinary consideration and their applications in research and pharmaceuticals are being quickly expanded. In addition to repressing gene expression, miRNA can also activate genes in some cases or even bring pseudo activity by themselves.

\section{Biological instability and short circulation half-life}

MiRNA or other RNA-based nanostructures, for instance, anti-miRNA oligonucleotides (AMO) have short half-life and immediately degraded in natural fluids by widespread nucleases. Particularly, nanostructures are more sensitive to natural changes, such as the change from in vitro to in vivo conditions.

\section{Reduced intracellular delivery}

In spite of the fact that pRNA has been shown to be a powerful nano-vector for delivery of miRNA, regardless it faces many difficulties, for example, industry scale synthesis and purification is not all that simple yet.

\section{Off target effects}

MiRNA activity depends on imperfect base-matching with target sequences, which may lead to lower specificity. Also, a miRNA may focus on a few obscure qualities in the meantime and one gene can be regulated by a few miRNAs [119], which indicates that its mode of action is more complicated than anticipated.

\section{Necessity of nanocarrier-mediated miRNA delivery}

Oligonucleotides like siRNA, anti-miRNA and synthetic miRNA mimics can be linked with nanocarriers which improves their resistance to nucleases [120]. The chances of immune rejection are reduced to many folds when nanocarriers are used to deliver oligonucleotides [121]. The function of nanoparticles can be modulated because nanocarriers can be easily modified with different molecules. For example, nanoparticles can be easily conjugated with proteins, antibodies and carbohydrates by modifying the surface with carboxyl and amino groups [122]. The therapeutic miRNA is delivered with high specificity when targeting ligand is attached on the nanoparticle surface [123]. Many obstacles are faced by miRNA while reaching its target site the body when delivered naked. So, miRNA can be linked with PEG coated, surface-passivized nanoparticles leading to miRNA protection from degradation, opsonization and enhances circulation. Due to the small size and ability to link cell penetrating peptides of nanoparticles, the cellular uptake of miRNA is enhanced resulting in many fold rise in cellular entry [124]. 
Table 2 Present scenario of miRNA therapeutics

\begin{tabular}{|c|c|c|c|c|}
\hline Company & Targeted miRNA & Disease & Technology & Status \\
\hline \multirow[t]{8}{*}{ Regulus Therapeutics } & miR-122 & Hepatitis C & Anti-miR & Preclinical \\
\hline & miR-10b & Glioblastoma & Anti-miR & Preclinical \\
\hline & $\operatorname{miR}-221$ & $\mathrm{HCC}$ & Anti-miR & Preclinical \\
\hline & miR-21 & Renal fibrosis & Anti-miR & Preclinical \\
\hline & miR-33 & Atherosclerosis & Anti-miR & Completed preclinical \\
\hline & miR-17 & Autosomal dominant polycystic kidney disease & Anti-miR & Preclinical \\
\hline & miR-27 & Cholestatic disease & Anti-miR & Discontinued \\
\hline & miR103/107 & Type-Il diabetes & Anti-miR & Phase-I \\
\hline Santaris Plasma & miR-122 & Hepatitis C & Anti-miR & Phase-Ila \\
\hline \multirow[t]{6}{*}{ Mirna therapeutics } & miR-34 & Primary liver cancer & Mimic & Phase-l \\
\hline & miR-155 & Hematological malignancies & Anti-miR & Completed preclinical \\
\hline & miR-215 & Cancer & Mimic & Preclinical \\
\hline & miR-101 & Cancer & Mimic & Preclinical \\
\hline & miR-16 & Cancer & Mimic & In pipeline \\
\hline & let-7 & Cancer & Mimic & In pipeline \\
\hline \multirow[t]{8}{*}{ miRagen therapeutics } & miR-92 & Peripheral artery disease & Anti-miR & Preclinical \\
\hline & miR-15/195 & Myocardial infarction & Anti-miR & Preclinical \\
\hline & miR-155 & Cutaneous T-cell lymphomas & Inhibition & Phase-I \\
\hline & miR-208 & Chronic heart failure & Inhibition & In pipeline \\
\hline & miR-143/145 & Vascular disease & Inhibition & In pipeline \\
\hline & miR-29 & Cardiac fibrosis & Inhibition & In pipeline \\
\hline & $\operatorname{miR}-451$ & Abnormal red blood cell production & Anti-miR & Discovered \\
\hline & miR-92 & Peripheral arterial disease & Inhibition & In pipeline \\
\hline
\end{tabular}

\section{Nanotechnology-assisted miRNA delivery}

In the recent years, nanotechnology has been through many advancements both in terms of novel material development [125] and applications in growing number of areas. These advancements have led to the development of novel DNA and RNA delivery systems for disease control that can be used instead of viral vectors. Variety of inorganic (gold, silver, calcium phosphate, graphene, quantum dots, iron oxide and silica), organic (chitosan, liposomes, proteins/peptides and aptamers) and polymers based nanomaterials can be used for the development of these non-viral vectors. These nanomaterials based delivery systems have several advantages over viral vector based delivery systems, which include decreased immune response and flexibility in design which allows them to be functionalized and targeted to specific sites with low cytotoxicity [126].

\section{Chitosan based nanomaterials}

Chitosan is a natural polysaccharide of $\beta-1-4$ linked $\mathrm{N}$-acetyl-D-glucosamine and $\mathrm{D}$-glucosamine. It is generally produced by deacetylation of chitin from crustacean shells. Due to its cationic nature, natural abundance, low toxicity, biodegradability and mucoadhesivity $[127,128]$ it has been used to as in vitro vector for DNA, [129-131] and miRNA delivery. McKiernan et al. targeted cystic fibrosis using miRNA based nano-medicine. They used cytosine and PEI based nano delivery method to target miR-126 [132]. Deng et al. reported that hyaluronic acidchitosan nanoparticle mediated delivery of miR-34a with doxorubicin, suppresses breast cancer [133]. Louw et al. found that chitosan mediated delivery of miRNA-124 reduces microglial cells in spinal cord injury in rat [134].

\section{Lipid/liposomes based nanomaterials}

Liposome mediated DNA/RNA/miRNA delivery is usually done with the help of cationic lipids (CLs) $[135,136]$. These lipids comprise a cationic head group and a linker to which a hydrophobic moiety is attached. The negatively charged phosphate group of the nucleic acids binds to the positive charge of head group [137]. Liposomes own attributes like less toxic, easy to handle and reduced risk of immunological rejection, which makes it a handy tool for using in non-viral DNA delivery [138, 139]. Lactosylated gramicidin based lipid nanoparticles were used to deliver anti-mir-155 to hepatocellular carcinoma [140]. Hsu et al. used cationic lipid nanoparticles to deliver miR-122 mimic to downregulate miR-122 in hepatocellular carcinoma [139]. Pramanik et al. used lipid based nanoparticles to deliver mimic miR-34a or miR-143/145 
to inhibit pancreatic cancer in mice [141]. Wu et al. delivered miR-29b or miR-133b using cationic lipoplex based vectors for the treatment of lung cancer [142]. Piao et al. used lipid based nanoparticles to deliver pre-miR-107 to inhibit tumorigenicity of head and neck squamous cell carcinoma [143]. Liu et al. used liposome based nanoparticles to deliver anti-miR-296 for inhibiting blood vessel formation in cancer cells [144].

\section{Protein and peptide nanomaterials}

Nucleic acid carriers designed with the help of proteins and peptides are widely explored to deliver nucleic acids and small non-coding RNA molecules because the nucleotides are condensed through electrostatic interactions with the positive charge of amino acids. Furthermore, amino acids add to endosomal escape, targeted delivery and bioreversible polyplex stabilization of system [145]. Oh et al. studied the effect of R3V6 peptide mediated delivery of anti-miR-21 in glioblastoma in animals [146]. Song et al. studied the effect of peptide mediated delivery of anti-miR-21 in glioblastoma [147]. Suh et al. studied the anti-cancer effects of peptide mediated delivery of miR-29b [148]. Peptide based nanocomplexes were developed to deliver anti-miR-199a to inhibit pancreatic cancer [149].

\section{Aptamers}

Aptamers are 3-D (three-dimensional) single chain DNA or RNA molecules that bind to a particular target molecule with high affinity and particularity [150]. Repeated rounds of selections known as "systematic evolution of ligands by exponential enrichment" (SLEX) is used to select aptamers from a combinatorial library of randomized sequences [151]. Aptamers can be used to target small molecules, nucleic acids, proteins, carbohydrates, whole cells and even organism. Aptamers possess high diversity and high specificity to target molecule which can be selected or isolated from the library. In addition to this, aptamers are highly stable and have very low chances of immunogenic rejection. MUC-1 aptamer was used for miR-29b mediated inhibition of PTEN methylation in ovarian cancer [152]. RNA nanoparticles containing anti-prostate-specific membrane antigen (PSMA) RNA aptamers were constructed to deliver anti-miR17 in cancer cells for the treatment of prostate cancer [153]. Systemic delivery of anti-miR-21 using epidermal growth factor targeting aptamer was used to block breast cancer in mouse [154]. RNA adapter GL21.T mediated delivery of miR-212 down regulates PED (apoptosis related protein) and restore TRAIL (TNF-related apoptosis inducing ligand) mediated cytotoxicity in lung cancer [155]. DNA aptamer based anti-human KIT sequences and mouse c-KIT aptamer targeted delivery of miR-26a protects mice from chemotherapy toxicity while suppressing tumour growth [156].

\section{Inorganic nanoparticles as carrier of miRNA}

Inferable from nano-measurement size to volume proportion and its strength, inorganic (metal) nanoparticles are as a rule broadly utilized as promising quality bearers in different biomedical applications. Inorganic nanomaterials have remarkable electrical and optical properties, biocompatibility and in addition low cytotoxicity [157].

\section{Gold nanoparticles}

Among the different metals, suitability of gold as nanoparticles is highest due to its inactive nature, ease of synthesis, high functionalization, ability, higher absorption coefficient, simplicity of location and potential ability of targeted capacity. Therefore, it is widely utilized for different applications including medication and gene delivery. Due to its remarkable stability, large surface area, surface modification and high biocompatibility gold nanoparticles can retain the native structure and enzymatic activity of the attached proteins or enzyme in the drug delivery. The instability and poly anionic nature of naked miRNAs impede efficient cellular uptake and reduce halflife. Viral delivery requires cloning miRNA mimics/inhibitors requiring costly modifications and both require toxic lipofection or electroporation. To address these challenges, unmodified miRNAs were delivered using cysteamine-functionalized gold nanoparticles (AuNPs) showing highest payload, lowest toxicity, fastest endosomal escape and increased half-lives [158]. Gold nanoparticles functionalized with synthetic miRNAs were able to deliver miRNA to prostate cancer cells [159]. In prostate and breast cancer, miR-145, a well-known tumour suppressor miRNA is strongly downregulated and gold nanoparticles are used for their delivery [160]. Conjugation of gold nanoparticles with miRNA was tested in cell transfection using multiple myeloma cells demonstrating efficient knockdown in the functional luciferase assay [161]. AuNP-miR-375 nanoparticles exhibit high cellular uptake and preserves miR-375's activities to suppress cellular proliferation, migration and colony formation and to induce apoptosis in hepato-carcinoma cells [162]. Anti-miRNA oligonucleotides which target miR-29b is known to downregulate myeloid cell leukaemia and are effectively delivered utilizing functionalized gold nanoparticles [163].

\section{Graphene nanoparticle}

Graphene is also an attractive nano-materials because of its optical, thermal and electrical properties [164]. The nanoparticles of poly (amidoamine) dendrimers-grafted gadolinium-functionalized nanographene oxide have 
proven to be an effective carrier for delivering chemotherapeutic drug and gene targeting agents such as miRNA to cancer cells [165].

\section{Quantum dot nanoparticle}

Quantum dots (QD) are semiconductor-based, monodisperse, nanometer-sized crystals [166], which can be synthesized by different methods including colloidal or plasma synthesis mechanism [167]. It was demonstrated that miR-26a-loaded QD nanocomplexes can up-regulate miR-26a expression, arrest cell cycle resulting in the inhibition of cancer cell proliferation in HepG2 cells [168]. It demonstrates that Quantum dot nanocarrier system has potential for early detection, monitoring and localized treatment of specific diseases.

\section{Silica nanoparticle}

Silica has also been used for miRNA delivery. Mesoporous silica nanoparticles have large surface area for functionalization and tunable pore size which makes it novel and ideal biomaterial for different therapeutic applications [169]. These have been used for delivery of miR-122 antagomir and small molecule inhibitors to achieve combination inhibition of its targeted miRNA in Huh7 cells. The first study which demonstrated silica nanoparticle based targeted delivery involved a tumour suppressive and pro-apoptotic miRNA miR-34a to neuroblastoma tumour-bearing mice for the treatment of neuroblastomas [170]. A multifunctional fluorescent nanoprobe with the AS1411 aptamer and a molecular beacon was co-immobilized on the surface of the fluorescent dye-doped silica nanoparticles for target cell specific delivery and intracellular miRNA imaging [72].

\section{Polymer mediated delivery of miRNA}

Both natural and synthetic polymers show variation in their structure, molecular weight together with the chemical properties of the repeat units(s), affect their physico-chemical properties. Due to the large diversity in polymers, polymer based nanomaterials have drawn interest as potential delivery vectors. Polymer mediated delivery provides unique advantage over liposome because of their stability in biological fluids after systemic administration. These are much suitable for industrial scale up as they require less time of preparation. Synthetic polymers include dendrimers, polyethyleneimines and polyphosphoesters.

\section{Polyethyleneimine (PEI)}

It is most extensively studied polymer for use in gene delivery. PEI is utilized for delivery of nucleic acid to the cells because of its buffering limit [171]. It is available as linear PEI or branched PEI. Linear PEI contains all secondary amines while branched PEI contains primary, secondary and tertiary amines. Furthermore, secondary and tertiary amines of the PEI impart buffering capacity. There are few studies which demonstrated the utilization of PEI for miRNA delivery [172-175]. Mir-145 and mir-33a mimics were delivered systemically using PEImiRNA complex that resulted in significant antitumor effects in colon carcinoma mouse xenograft model [174]. These studies reveal that PEI coated nanospheres have the potential to be used as the novel class of anticancer agents.

\section{Dendrimers}

Dendrimers are mono disperse, nanosized, highly branched macromolecules which are chemically synthesized in a controlled manner to obtain varied surface functionalities. These are important class of polymers used in delivery of oligonucleotides. They have high drug loading capacity either by encapsulation or conjugation. Delivery of mir-7 to human brain glioma cells (U251) using PAMAM dendrimers had higher transfection efficiency and improved therapeutic effects in vitro and in vivo were achieved [176]. The co-delivery of anti-miR-21 using PAMAM dendrimers significantly improved the cytotoxicity of $5-\mathrm{FU}$, reduced migration and enhanced the apoptosis of U251 glioblastoma cells9 [177]. When mir-126 was delivered to HUVEC cells through poly arginine and RGD ( 9 arginine-glycine-aspartic acid)-modified dendrimers, it significantly reduced their proliferation and tube formation [178]. Dendrimers achieve the goal of balanced low toxicity and high potency to effectively deliver miRNA.

\section{PLGA based nanoparticles}

Poly(lactic-co-glycolic acid) PLGAs are a family of waterinsoluble polymers that have been widely used in biomedical applications [179]. These can be readily formed into nanoparticles which entrap biologically active molecules [180, 181]. PLGA particles overcome several limitations which are faced by current miRNA therapy because they can protect nucleic acids from degradation, achieve high loading capacity and different modifications can be applied [182]. In addition, poly(lactic-co-glycolic acid) are safe, biodegradable, and they have a long history of success in enhancing the delivery of therapeutic agents. Reduction in tumour growth was observed by polymer (PLGA-b-PEG) mediated delivery of anti-miR-10b and anti-miR-21 in mice [183]. Therapeutic efficacy of antimiR-21 and gemcitabine co-encapsulated PEGylated PLGA nanoparticles against hepatocellular carcinoma was studied by Devulapally et al. [183]. The effect of codelivery of doxorubicin and miR-542-3p using hyaluronic acid decorated PEI-PLGA nanoparticle against breast 
cancer was studied [184]. Apoptotic effects were significantly enhanced by combined delivery of orlistat loaded nanoparticles and doxorubicin or anti-miR-21 loaded nanoparticles using PLGA-PEG-nanoparticles in breast cancer [185]. New insights in neurodegenerative disease (Parkinson's disease) were gained by the use of miR-124PLGA nanoparticles [186].

\section{Silencing miRNA via RNA nanotechnology for targeted therapeutic delivery}

The major breakthrough in the field of biological sciences came with the discovery of RNA interference (RNAi) technology in 1998 and has created boulevard for the treatment of various deadly diseases like cancer [187]. In RNAi, a short 21-23 nucleotide double stranded RNA sequence is used to regulate the gene expression. MiRNA and siRNA are two central molecules to RNA interference [188]. While most of the siRNA are artificial sequences, a few endogenous siRNA sequences do occur, but miRNA are endogenous and target multiple genes [189]. RNAi therapy can be used to target any known mRNA sequences that can use to treat any disease that was previously undruggable. RNA nanoparticles are constructed such that the Dicer endonuclease can approach the dsRNA encoding sequences and can generate functional miRNA that can be loaded into RISC (RNAinduced silencing complex) and thereby modulate gene expression by selectively directing mRNAs. Anti-miRNA nanoparticles were effectively used to downregulate a tumour causing miRNAs and increase an endogenous tumour suppressing miRNAs. Triple negative breast cancer growth was inhibited by pRNA-3WJ nanoparticles loaded with EGFR-targeting RNA aptamer and antimiR-21. Upon systemic injection into mice with breast cancer, RNA nanoparticles harbouring EGFR aptamer effectively targeted and internalized tumour cells via receptor mediated endocytosis [154]. After entering the tumour cells the anti-miR-21 binds to the target region thereby blocking miR-21 tumorigenic properties [190]. In a similar way, pRNA-3WJ nanoparticles loaded with PSMA aptamers and anti-miR-21 were used to target subcutaneous prostate xenografts and were found to inhibit tumour growth in animal models [153].

\section{MiRNA delivery in plants}

Like animals, the RNA nanoparticle based miRNA delivery technique can be utilised in plants to target those biotic and abiotic stresses against which there is no effective strategy for combating them. RNA nanotechnology may revolutionize the crop improvement programmes which will be a step towards food security worldwide. The artificial microRNA (amiRNA) technology can target endogenous miRNA precursors to give rise small RNA guiding gene silencing in plants and animals [191-194]. Oligonucleotide substitutions that mimic the intact secondary structure of endogenous miRNA precursors may lead to targeted silencing of desired gene $[195,196]$. The amiRNA technique was used for the first time in human cell lines followed by Arabidopsis [192, 194]. The use of amiRNAs short sequences is beneficial over long hairpin mediated silencing because of reduced off-target effects on host genes and reduced risk of binding to non-target pathogen for use in agriculture. Recently plant resistance to various pathogens has been achieved by expression of artificial miRNA in transgenic Arabidopsis plants providing resistance to turnip yellow mosaic virus and turnip mosaic virus. This was developed using amiRP69 $9^{159}$ and amiR-Hc-Pro ${ }^{159}$ by Niu et al. [197]. AmiRNA based on Arabidopsis pre miRNA159a was also used to develop transgenic Arabidopsis plants that confers resistance against cucumber mosaic virus [195]. AmiRNA against Hc-Pro of Potato virus Y (PVY) and TGBp1/p25 of Potato virus X (PVX) were designed using Arabidopsis thaliana miRNA159a, miRNA167b and miRNA171a as backbone. Transgenic tobacco plants showed resistance against PVY and PVX [198]. In wheat, resistance against wheat streak mosaic virus (WSMV) was developed using rice miR359 to construct amiRNA precursor, FanGuard (FGmiR395) under a strong constitutive promoter. The transgenic lines showed three types of resistance, i.e. complete resistance, initially immune but resistance break over time and initial resistance followed by plant recovery [199]. Arabidopsis pre-miRNA159a was used to design amiRNA against Watermelon silver motile virus (WSMoV). Six single (A, B1, B2, C, D and E) and two triple (AB1E and $\mathrm{B} 2 \mathrm{DC})$ motif targeting constructs were designed and transformed in Nicotiana benthamiana. Triple amiRNA expressing transgenic lines showed complete resistance against WSMoV [200]. Endogenous gene silenced in various plants species using amiRNA technique are listed in Table 3.

\section{Challenges associated with RNA nanotechnology}

Construction of RNA nanoparticle involves coupling of functionalities, module joining, subunit labelling and chemical modification of nucleic acid molecules. Both chemical and enzymatic approaches are utilized in synthesizing RNA building blocks. Although the technology has gained much advancement, still there is a scope for improvement.

\section{RNA structure prediction}

One of the major challenges in RNA nanotechnology is to know the correct structure of the folded RNA nanoparticle. Because of unusual folding properties, the rules that clarify folding of RNA molecules are yet to 
Table 3 Artificial micro RNA used for disease resistance in plants

\begin{tabular}{|c|c|c|c|}
\hline Plant species & Disease & amiRNA/Pre-miR backbone & References \\
\hline Arabidopsis & Turnip yellow mosaic virus and Turnip mosaic virus & amiR-P69 ${ }^{159}$ and amiR-Hc-Pro ${ }^{159}$ & {$[197]$} \\
\hline Tobacco & Cucumber mosaic virus & amiR-2b & {$[201]$} \\
\hline Tobacco & Cassava brown streak virus & amiR-159a & {$[202]$} \\
\hline Tobacco & Potato virus $Y$ & amiR-HC-Pro & [203] \\
\hline Grapes & Grapevine fan leaf virus & $\operatorname{amiR}^{\mathrm{CP}}-2$ & {$[204]$} \\
\hline Tomato & Viral infection & amiR-2a/b & {$[205]$} \\
\hline Tobacco & Potato virus $Y$ and potato virus $X$ & amiR-Hc-Pro ${ }^{159 a}$ amiR-Hc-Pro ${ }^{167 b}$ amiR-Hc-Pro ${ }^{171 a}$ & {$[195]$} \\
\hline Arabidopsis & Cucumber mosaic virus & amiR-159a & {$[198]$} \\
\hline Cotton & Cotton leaf curl virus & Pre-miR-169a & {$[206]$} \\
\hline Wheat & Wheat streak mosaic virus & Pre-miR395 & {$[199]$} \\
\hline Arabidopsis & Water melon silver mottle virus & Pre-miR-159a & {$[200]$} \\
\hline Tomato & Tomato leaf curl virus & amiR-AV1-3 & {$[207]$} \\
\hline Arabidopsis & Turnip mosaic virus & amiR ${ }^{159}-P 69$ & {$[208]$} \\
\hline Rice & Rice stripe virus and Rice black streaked swarf virus & Osa-pre-miR528 & {$[209]$} \\
\hline Barley & Wheat dwarf virus & huv-pre-miR171 & {$[210]$} \\
\hline Tobacco & Tomato spotted wilt virus & Pre-miR-159a & {$[211]$} \\
\hline
\end{tabular}

be classified. With the use of RNA 2D structure prediction programme, only $70 \%$ of structure can be predicted accurately [212, 213]. Though various online resources like Mfold, 233 RNA designer, 234 Sfold, 235 NUPACK, 115 nanofolder, 236 and hyperfold, 182 have been developed, prediction of accurate RNA structure and folding remains a major problem. RNA 3D and 4D structure prediction is even more subtle. Advancements in bioinformatics tools have added insights in RNA structure prediction and computing intermolecular interactions but still more refined tools are expected [214-216].

\section{Stability}

RNA in its native form is sensitive to nucleases (RNases). This instability has become a limited factor for its application in nano material construction. With the advancement in technology, several steps have been taken to increase the stability of RNA molecule which includes; chemical modification of bases (5-Br-Ura and 5-I-Ura); alterations in phosphate linking (phosphothioate, boron phosphate) and changes like $2^{\prime}-\mathrm{F}, 2^{\prime}-\mathrm{O}-\mathrm{Me}, 2^{\prime}-\mathrm{NH}_{2}$ on $\mathrm{C} 2^{\prime}$ carbon $[217,218]$. RNA stability can also be increased by synthesis of peptide nucleic acids, locked nucleic acids with bridging and $3^{\prime}$ capping $[219,220]$. Among all the 2 '-fluorine modification is most suitable because its effect on RNA folding and function is minimal [221].

\section{In vivo half-life and retention time}

In vivo retention time of the nanoparticle is determined by its size making it a critical factor in RNA nanotechnology. Scientific reports suggest that $10-100 \mathrm{~nm}$ range particles are optimal for non-viral vector based delivery.
Particles within this range are large enough to be retained in the body and small enough to bind the cellular receptors and can cross cell membrane [222]. Hence optimal size of RNA nanoparticle is important for its biodistribution and higher retention time for in vivo delivery. The half-life of chemically modified RNA nanoparticles was found to be $5-10 \mathrm{~h}$ [223]. So, chemicals modifications have somehow reduced the problem associated RNA nanoparticle half-life and retention time but still, there is a lot of scope for improvement.

\section{Limited carrying capacity}

Presently, RNA nanoparticles have limited carrying capacity and is a major problem associated with today's RNA nanotechnology. Only the terminal end of the nanoparticle can be labelled with the molecule, particularly of smaller size. Whole chain labelling can increase the carrying capacity of the nanoparticle but may lead to misfolding of the nanoparticle due to steric hindrance ultimately leading to release of the target molecule. Computational methods can be employed to locate the site where the target molecule can be introduced without disrupting the nanoparticle. The carrying capacity of RNA nanoparticles can be increased by constructing dendrimers and RNA dendrimers have been developed up to generation 4 [224]. Dendrimers can increase the carrying capacity because of branched architecture and hence can lead to increased delivery of therapeutic RNA. But over saturation of therapeutic RNA can lead to gene knockdown and unrelated binding and can cause cytotoxicity $[225,226]$. Hence, RNA nanoparticles with lower carrying capacity are advantageous in animal studies because 
of lower toxicity. Thus development of RNA nanoparticles with high carrying capacity and lower toxicity is a big challenge.

\section{Scaling up}

High cost of production and purification of RNA nanoparticles has restricted its use in clinical applications. Typically, RNA nanoparticles are mainly designed within the range of chemical synthesis (maximum of $80 \mathrm{nt}$ ). With the advancement in the technology, the cost of oligosynthesis is significantly reduced. Now $10 \mathrm{~g}$ of RNA can be synthesized per cycle. However, large scale purification is still a problem. Gel electrophoresis and high-performance liquid chromatography have limited capabilities giving low yield. Recently, ultracentrifugation has been employed for purification of RNA nanoparticles with high yield [227].

\section{Endosome escape}

Receptor mediated endocytosis is one of the way through which RNA nanoparticles can be delivered in human body. Thus, tracking of intracellular RNA nanoparticle is another major challenge with respect to RNA nanotechnology. Similar to endocytosis pathway, RNA nanoparticles first forms the early endosomal vesicle. After sorting, RNA nanoparticles are shifted to late endosomes and then to lysosomes, where these particles get entrapped without reaching the target. An $8 \mathrm{nt}$, anti-miR LNA fragment was successful in endosomal escape in RNA nanoparticle mediated cancer therapy [154], but the efficacy of non-coding RNA escape from RNA nanoparticle is still a problem as it is found that cancer regression via this method is relatively low [228, 229]. Various tools have been employed to overcome this problem which includes use of acid cleavable linkers like acetyl, hydrazone and maleic amide and use of acid protonating groups like amino esters and sulphonamide [230].

\section{Conclusion}

With the natural occurrence of miRNAs and their role in disease detection and prevention, these small RNAs prove to be a brilliant possibility for use as novel therapeutics. With effective delivery of miRNAs to diseased cells, regulation of specific gene expression and modification of cellular function can be accomplished however successful detection, targeting and delivery of the miRNAs are required. Several distinctive methodologies have been utilised for the delivery of miRNA and different detection procedures are employed using different nanoparticles. However, limitations associated with miRNA delivery can be encountered using RNA nanotechnology, which aims at developing RNA nanoparticles containing a targeting molecule and additionally miRNA. The self-modelling quality of RNA can be used as a powerful technique to design and structure RNA nanoparticles through the interchange of biological, chemical, physical and computational sciences. Inspite of difficulties associated with RNA nanotechnology, this emerging field has an extraordinary application in the field of medicine, biotechnology, synthetic biology and nanotechnology, especially in the field of therapeutics where it can be utilized in the treatment of savage diseases like malignancy and viral ailments. Nanotechnology works with smallest possible particles which raises hopes for improving agricultural productivity. It has also been suggested that artificial miRNA poses fewer biosafety or environmental problems when applied to agriculture compared with transgenic breeding. Nanostructured formulation through mechanisms such as targeted delivery or slow controlled release mechanisms and conditional release, could lead to precision release of active ingredients in response to environmental triggers. RNA nanotechnology in plant science holds promise to detect and control various biotic and abiotic stresses through use of miRNA based biomarkers which will revolutionize crop protection. RNA nanotechnology will help to develop new area of research developing biosensors for forecasting and early detection of plant disease.

\section{Future outlook}

High thermodynamic stability and amazing diversity of RNA and its structure and function holds great promise over DNA Nanotechnology. Since it can be chemically modified, it has been efficiently utilized in human and animal therapeutics, however, plant nanotechnology is still an emerging area of research and its applications in plant disease detection and protection is yet to be seen. Nanotechnology assisted strategies will play key role in integrated pest management supplementing conventional methods in view of environmental concerns. Plant transformation has been used in improving disease resistance in crop plants using overexpression of disease resistance genes, RNAi etc. Synthetic miRNAs can be of particular use and provide excellent choice in these approaches. Delivery of synthetic miRNA in plants is a major concern but recently clay nanoparticles have been used in delivering miRNA for viral protection. The making of synthetic RNA is not cost effective at present; the new developments in this field may lead to novel cost effective strategies. RNA nanoparticles and their use as spray over plants may be advantageous as it is biocompatible, biodegradable and non-toxic making this approach highly flexible and safe.

Nanoparticles synthesized from plants extracts can also be utilized for direct delivery of synthetic miRNA as an efficient method in comparison to Agrobacterium and other direct gene transfer methods in plants. 
Nanotechnology assisted targeting of miRNA can help in mitigating pests and abiotic stresses under climate change scenario. The miRNAs and transcription factors, being the regulatory molecules, promise to target multigenic traits since these regulatory networks overlap.

Rapid and early detection of miRNA responsible for disease in plants is still a challenging task. The miRNA can be detected using nanoparticle tags in diseased state using miRNA assay. The association of electrocatalytic nanoparticles tags to hybridized miRNA molecules generates measurable current upon adding substrate to the solution providing better detection limit over optical miRNA assay. There could be new innovative approaches as well for miRNA detection and their use in therapeutics in humans and animals and crop protection as well in near future.

\section{Abbreviations}

DNA: deoxyribonucleic acid; RNA: ribonucleic acid; miRNA: microRNA; RNAi: RNA interference; nt: nucleotides; pRNA: packaging RNA; kb: kilo base pairs; GTP: guanosine triphosphate; kDa: kilo daltons; RISC: RNA induced silencing complex; AGO: argonaute; Pol II: polymerase Il; amiRNA: artificial microRNA; PLGA: poly(lactic-co-glycolic acid); PEl: polyethyleneimine; siRNA: small interfering RNA; PEG: polyethylene glycol; osa: Oryza sativa; zju: Ziziphus jujube.

\section{Authors' contributions}

VC and SJ performed analysis of literature and wrote the paper, NRY supervised and corrected the manuscript. All authors read and approved the final manuscript.

\section{Acknowledgements}

Not applicable.

\section{Competing interests}

The authors declare that they have no competing interests.

\section{Availability of data and materials}

Not applicable.

\section{Consent for publication}

Not applicable.

Ethics approval and consent to participate

Not applicable.

\section{Funding}

No funding was available for this publication.

\section{Publisher's Note}

Springer Nature remains neutral with regard to jurisdictional claims in published maps and institutional affiliations.

Received: 12 October 2017 Accepted: 7 April 2018

Published online: 13 April 2018

\footnotetext{
References

1. Seeman NC. Nanomaterials based on DNA. Annu Rev Biochem. 2010;79:65-87. https://doi.org/10.1146/ annurev-biochem-060308-102244.
}

2. Shu Y, Shu D, Haque F, Guo P. Fabrication of pRNA nanoparticles to deliver therapeutic RNAs and bioactive compounds into tumor cells. Nat Protoc. 2013;8:1635-59.

3. Calin GA, Dumitru CD, Shimizu M, Bichi R, Zupo S, Noch E, et al. Nonlinear partial differential equations and applications: frequent deletions and down-regulation of micro-RNA genes miR15 and miR16 at 13q14 in chronic lymphocytic leukemia. Proc Natl Acad Sci. 2002;99:15524-9. https://doi.org/10.1073/pnas.242606799.

4. Bartel DP. MicroRNAs: genomics, biogenesis, mechanism, and function. Cell. 2004;116:281-97.

5. Gregory Rl, Chendrimada TP, Shiekhattar R. MicroRNA biogenesis: isolation and characterization of the microprocessor complex. Methods Mol Biol. 2006;342:33-47.

6. Lee Y, Jeon K, Lee J-T, Kim S, Kim VN. MicroRNA maturation: stepwisee processing and subcellular localization. EMBO J. 2002;21:4663-70.

7. Lee Y, Ahn C, Han J, Choi H, Kim J, Yim J, et al. The nuclear RNase III Drosha initiates microRNA processing. Nature. 2003;425:415-9.

8. Gregory RI, Yan K-P, Amuthan G, Chendrimada T, Doratotaj B, Cooch N, et al. The microprocessor complex mediates the genesis of microRNAs. Nature. 2004;432:235-40.

9. Han J, Lee Y, Yeom KH, Nam JW, Heo I, Rhee JK, et al. Molecular basis for the recognition of primary microRNAs by the Drosha-DGCR8 complex. Cell. 2006;125:887-901.

10. Auyeung VC, Ulitsky I, McGeary SE, Bartel DP. Beyond secondary structure: primary-sequence determinants license Pri-miRNA hairpins for processing. Cell. 2013;152:844-58.

11. Yi R, Qin Y, Macara IG, Cullen BR. Exportin-5 mediates the nuclear export of pre-microRNAs and short hairpin RNAs. Genes Dev. 2003;17:3011-6.

12. Bohnsack MT, Czaplinski K, Gorlich D. Exportin 5 is a RanGTP-dependent dsRNA-binding protein that mediates nuclear export of pre-miRNAs. RNA. 2004;10:185-91.

13. Lund E, Güttinger S, Calado A, Dahlberg JE, Kutay U. Nuclear export of microRNA. Science. 2004:303:95-8.

14. Bernstein E, Caudy AA, Hammond SM, Hannon GJ. Role for a bidentate ribonuclease in the initiation step of RNA interference. Nature. 2001;409:363-6.

15. Zhang H, Kolb FA, Jaskiewicz L, Westhof E, Filipowicz W. Single processing center models for human Dicer and bacterial RNase III. Cell. 2004;118:57-68.

16. Tsutsumi A, Kawamata T, Izumi N, Seitz H, Tomari Y. Recognition of the pre-miRNA structure by Drosophila Dicer-1. Nat Struct Mol Biol. 2011:18:1153-8.

17. Hammond SM, Boettcher S, Caudy AA, Kobayashi R, Hannon GJ. Argonaute2, a link between genetic and biochemical analyses of RNAi. Science. 2001;293:1146-50.

18. Mourelatos Z, Dostie J, Paushkin S, Sharma A, Charroux B, Abel L, et al. miRNPs: a novel class of ribonucleoproteins containing numerous microRNAs. Genes Dev. 2002:16:720-8.

19. Tabara H, Sarkissian M, Kelly WG, Fleenor J, Grishok A, Timmons L, et al. The rde-1 gene, RNA interference, and transposon silencing in $C$ elegans. Cell. 1999;99:123-32.

20. Miyoshi T, Ito K, Murakami R, Uchiumi T. Structural basis for the recognition of guide RNA and target DNA heteroduplex by Argonaute. Nat Commun. 2016;7:11846.

21. Arribas-Hernández L, Kielpinski L, Brodersen P. mRNA decay of most Arabidopsis miRNA targets requires slicer activity of AGO1. Plant Physiol. 2016;171:00231.

22. Kawamata T, Tomari Y. Making RISC. Trends Biochem Sci. 2010:35:368-76.

23. Axtell MJ, Westholm JO, Lai EC. Vive la différence: biogenesis and evolution of microRNAs in plants and animals. Genome Biol. 2011;12:221.

24. Chang S-S, Zhang Z, Liu Y. RNA interference pathways in fungi: mechanisms and functions. Annu Rev Microbiol. 2012;66:305-23.

25. Ma X, Tang Z, Qin J, Meng Y. The use of high-throughput sequencing methods for plant microRNA research. RNA Biol. 2015;6286:37-41.

26. Rogers $\mathrm{K}$, Chen X. Biogenesis, turnover, and mode of action of plant microRNAs. Plant Cell. 2013;25:2383-99.

27. Ha M, Kim VN. Regulation of microRNA biogenesis. Nat Rev Mol Cell Biol. 2014;15:509-24. https://doi.org/10.1038/nrm3838.

28. Baranauskè S, Mickutè M, Plotnikova A, Finke A, Venclovas Č, Klimašauskas $\mathrm{S}$, et al. Functional mapping of the plant small RNA 
methyltransferase: HEN1 physically interacts with HYL1 and DICER-LIKE 1 proteins. Nucleic Acids Res. 2015;43:2802-12.

29. Ramachandran V, Chen X. Degradation of microRNAs by a family of exoribonucleases in Arabidopsis. Science. 2008;321:1490-2.

30. Meyer RC, Honig G, Brandt R, Arana-Ceballos F, Neitsch C, Reuter G, et al. Overexpression of Arabidopsis thaliana ERI, the homolog of $C$. elegans enhancer of RNA interference, leads to enhanced growth. Front Plant Sci. 2015;6:531.

31. Arndt GM, Dossey L, Cullen LM, Lai A, Druker R, Eisbacher M, et al. Characterization of global microRNA expression reveals oncogenic potential of miR-145 in metastatic colorectal cancer. BMC Cancer. 2009;9:374. https://doi.org/10.1186/1471-2407-9-374.

32. Cummins JM, Velculescu VE. Implications of micro-RNA profiling for cancer diagnosis. Oncogene. 2006;25:6220-7.

33. Akao Y, Nakagawa Y, Naoe T. MicroRNAs 143 and 145 are possible common onco-microRNAs in human cancers. Oncol Rep. 2006;16:845-50.

34. Michael MZ, O'Connor SM, van HolstPellekaan NG, Young GP, James RJ. Reduced accumulation of specific microRNAs in colorectal neoplasia. Mol Cancer Res. 2003;1:882-91.

35. Yanaihara N, Caplen N, Bowman E, Seike M, Kumamoto K, Yi M, et al. Unique microRNA molecular profiles in lung cancer diagnosis and prognosis. Cancer Cell. 2006;9:189-98.

36. Zhao J-P, Jiang X-L, Zhang B-Y, Su X-H. Involvement of microRNAmediated gene expression regulation in the pathological development of stem canker disease in Populus trichocarpa. PLoS ONE. 2012;7:e44968. https://doi.org/10.1371/journal.pone.0044968.

37. Yang L, Jue D, Li W, Zhang R, Chen M, Yang Q. Identification of MiRNA from eggplant (Solanum melongena L.) by small RNA deep sequencing and their response to Verticillium dahliae infection. PLOS ONE. 2013;8:e72840.

38. Gao R, Wan ZY, Wong SM. Plant growth retardation and conserved miRNAs are correlated to hibiscus chlorotic rings pot virus infection. PLOS ONE. 2013:8:1-11.

39. Wu F, Shu J, Jin W. Identification and validation of miRNAs associated with the resistance of maize (Zea mays $\mathrm{L}$.) to Exserohilum turcicum. PLoS ONE. 2014;9:1-8.

40. Abreu PMV, Gaspar CG, Buss DS, Ventura JA, Ferreira PCG, Fernandes PMB. Carica papaya microRNAs are responsive to Papaya meleira virus infection. PLOS ONE. 2014;9:e103401.

41. Yang J, Zhang F, Li J, Chen JP, Zhang HM. Integrative analysis of the microRNAome and transcriptome illuminates the response of susceptible rice plants to rice stripe virus. PLoS ONE. 2016;11:1-21.

42. Shao F, Zhang Q, Liu H, Lu S, Qiu D. Genome-wide identification and analysis of MicroRNAs involved in witches'-broom phytoplasma response in Ziziphus jujuba. PLoS ONE. 2016;11:1-17.

43. Ouyang S, Park G, Atamian HS, Han CS, Stajich JE, Kaloshian I, et al. MicroRNAs suppress NB domain genes in tomato that confer resistance to Fusarium oxysporum. PLoS Pathog. 2014;10:e1004464.

44. Feng H, Duan X, Zhang Q, Li X, Wang B, Huang L, et al. The target gene of tae-miR164, a novel NAC transcription factor from the NAM subfamily, negatively regulates resistance of wheat to stripe rust. Mol Plant Pathol. 2014;15:284-96.

45. Zhang Q, Li Y, Zhang Y, Wu C, Wang S, Hao L, et al. Md-miR156ab and Md-miR395 target WRKY transcription factors to influence apple resistance to leaf spot disease. Front Plant Sci. 2017:8:526.

46. Hanemian M, Barlet X, Sorin C, Yadeta KA, Keller H, Favery B, et al. Arabidopsis CLAVATA1 and CLAVATA2 receptors contribute to Ralstonia solanacearum pathogenicity through a miR169-dependent pathway. New Phytol. 2016;211:502-15.

47. Li H, Fan J, Yin Z, Wang F, Chen C, Wang DW, et al. Identification of cardiac-related circulating microRNA profile in human chronic heart failure. Oncotarget. 2010;1:33-45. http://www.oncotarget.com/ fulltext/6631.

48. Sala V, Bergerone S, Gatti S, Gallo S, Ponzetto A, Ponzetto C, et al. MicroRNAs in myocardial ischemia: identifying new targets and tools for treating heart disease. New frontiers for miR-medicine. Cell Mol Life Sci. 2014;71:1439-52.

49. van Empel VPM, De Windt $L$, da Martins PA. Circulating miRNAs: reflecting or affecting cardiovascular disease? Curr Hypertens Rep 2012;14:498-509. https://doi.org/10.1007/s11906-012-0310-7.
50. Fichtlscherer S, De Rosa S, Fox H, Schwietz T, Fischer A, Liebetrau C, et al. Circulating microRNAs in patients with coronary artery disease. Circ Res. 2010;107:677-84.

51. Zampetaki A, Kiechl S, Drozdov I, Willeit P, Mayr U, Prokopi M, et al. Plasma MicroRNA profiling reveals loss of endothelial MiR-126 and other MicroRNAs in type 2 diabetes. Circ Res. 2010;107:810-7.

52. Gallagher IJ, Scheele C, Keller P, Nielsen AR, Remenyi J, Fischer CP, et al. Integration of microRNA changes in vivo identifies novel molecular features of muscle insulin resistance in type 2 diabetes. Genome Med. 2010;2:9.

53. Kong L, Zhu J, Han W, Jiang $X$, Xu M, Zhao Y, et al. Significance of serum microRNAs in pre-diabetes and newly diagnosed type 2 diabetes: a clinical study. Acta Diabetol. 2011;48:61-9.

54. Karolina DS, Tavintharan S, Armugam A, Sepramaniam S, Pek SL, Wong $M T$, et al. Circulating miRNA profiles in patients with metabolic syndrome. J Clin Endocrinol Metab. 2012;97:E2271-6.

55. Nielsen LB, Wang C, Sørensen K, Bang-Berthelsen CH, Hansen L, Andersen M-LM, et al. Circulating levels of microRNA from children with newly diagnosed type 1 diabetes and healthy controls: evidence that miR-25 associates to residual beta-cell function and glycaemic control during disease progression. Exp Diabetes Res. 2012;2012:896362. http:// www.hindawi.com/journals/jdr/2012/896362/.

56. Salas-Pérez F, Codner E, Valencia E, Pizarro C, Carrasco E, Pérez-Bravo F. MicroRNAs miR-21a and miR-93 are down regulated in peripheral blood mononuclear cells (PBMCs) from patients with type 1 diabetes. Immunobiology. 2013;218:733-7.

57. Sebastiani G, Spagnuolo I, Patti A, Grieco FA, Cataldo D, Ferretti E, et al, MicroRNA expression fingerprint in serum of type 1 diabetic patients. Diabetologia. 2012;55:S48-S48.

58. Zhao C, Dong J, Jiang T, Shi Z, Yu B, Zhu Y, et al. Early second-trimester serum miRNA profiling predicts gestational diabetes mellitus. PLoS ONE. 2011;6:e23925.

59. Huang Z, Huang D, Ni S, Peng Z, Sheng W, Du X. Plasma microRNAs are promising novel biomarkers for early detection of colorectal cancer. Int J Cancer. 2010;127:118-26.

60. Iorio MV, Ferracin M, Liu CG, Veronese A, Spizzo R, Sabbioni S, et al. MicroRNA gene expression deregulation in human breast cancer. Cancer Res. 2005;65:7065-70.

61. Iorio MV, Visone R, Di Leva G, Donati V, Petrocca F, Casalini P, et al. MicroRNA signatures in human ovarian cancer. Cancer Res. 2007;67:8699-707.

62. Roa W, Brunet B, Guo L, Amanie J, Fairchild A, Gabos Z, et al. Identification of a new microRNA expression profile as a potential cancer screening tool. Clin Investig Med. 2010;33:124. http://cimonline.ca/index.php/ cim/article/view/12351.

63. Szczyrba J, Loprich E, Wach S, Jung V, Unteregger G, Barth S, et al. The microRNA profile of prostate carcinoma obtained by deep sequencing. Mol Cancer Res. 2010;8:529-38.

64. Schaefer A, Jung M, Mollenkopf H-J, Wagner I, Stephan C, Jentzmik F, et al. Diagnostic and prognostic implications of microRNA profiling in prostate carcinoma. Int J Cancer. 2010;126:1166-76.

65. Kelly B, Miller N, Sweeney K, Durkan G, Rogers E, Walsh K, et al. A circulating microRNA signature as a biomarker for prostate cancer in a high risk group. J Clin Med. 2015;4:1369-79.

66. Casanova-Salas I, Rubio-Briones J, Calatrava A, Mancarella C, Masiá E, Casanova J, et al. Identification of miR-187 and miR-182 as biomarkers of early diagnosis and prognosis in patients with prostate cancer treated with radical prostatectomy. J Urol. 2014;192:252-9.

67. Sun $X Y$, Zhang J, Niu W, Guo W, Song HT, Li HY, et al. A preliminary analysis of microRNA as potential clinical biomarker for schizophrenia. Am J Med Genet. 2015;168:170-8.

68. Mundali Vasu M, Anitha A, Thanseem I, Suzuki K, Yamada K, Takahashi $\mathrm{T}$, et al. Serum microRNA profiles in children with autism. Mol Autism. 2014;5:40.

69. Tan L, Yu J-T, Tan M-S, Liu Q-Y, Wang H-F, Zhang W, et al. Genome-wide serum microRNA expression profiling identifies serum biomarkers for Alzheimer's disease. J Alzheimers Dis. 2014;40:1017-27.

70. Wang J, Yu J-T, Tan L, Tian Y, Ma J, Tan C-C, et al. Genome-wide circulating microRNA expression profiling indicates biomarkers for epilepsy. Sci Rep. 2015;5:9522. 
71. Kasimanickam V, Kastelic J. Circulating cell-free mature microRNAs and their target gene prediction in bovine metritis. Sci Rep. 2016;6:29509.

72. Li X, Zhu L, Liu X, Sun X, Zhou Y, Lang Q, et al. Differential expression of microRNAs in porcine parvovirus infected porcine cell line. Virol J. 2015:12:128.

73. Lawless N, Foroushani ABK, McCabe MS, O'Farrelly C, Lynn DJ. Next generation sequencing reveals the expression of a unique miRNA profile in response to a Gram-positive bacterial infection. PLOS ONE. 2013;8:e57543.

74. Malvisi M, Palazzo F, Morandi N, Lazzari B, Williams JL, Pagnacco G, et al. Responses of bovine innate immunity to Mycobacterium avium subsp. Paratuberculosis infection revealed by changes in gene expression and levels of MicroRNA. PLoS ONE. 2016;11:1-23.

75. Casas E, Cai G, Kuehn LA, Register KB, McDaneld TG, Neill JD. Association of microRNAs with antibody response to Mycoplasma bovis in beef cattle. PLOS ONE. 2016;11:e0161651. https://doi.org/10.1371/journal. pone.0161651.

76. Bester R, Burger JT, Maree HJ. Differential expression of miRNAs and associated gene targets in grapevine leafroll-associated virus 3-infected plants. Arch Virol. 2017;162:987-96.

77. Kasschau KD, Xie Z, Allen E, Llave C, Chapman EJ, Krizan KA, et al. P1/ HC-Pro, a viral suppressor of RNA silencing, interferes with Arabidopsis development and miRNA function. Dev Cell. 2003;4:205-17.

78. Chen J, Li WX, Xie D, Peng JR, Ding SW. Viral virulence protein suppresses RNA silencing-mediated defense but upregulates the role of microRNA in host gene expression. Plant Cell. 2004;16:1302-13.

79. Zhang X, Zhao H, Gao S, Wang W-C, Katiyar-Agarwal S, Huang H-D, et al. Arabidopsis Argonaute 2 regulates innate immunity via miRNA393*mediated silencing of a golgi-localized SNARE gene, MEMB12. Mol Cell. 2011;42:356-66.

80. Wong J, Gao L, Yang Y, Zhai J, Arikit S, Yu Y, et al. Roles of small RNAs in soybean defense against Phytophthora sojae infection. Plant J. 2014;79:928-40.

81. Zhang Y, Wang W, Chen J, Liu J, Xia M, Shen F. Identification of miRNAs and their targets in cotton inoculated with Verticillium dahliae by high-throughput sequencing and degradome analysis. Int J Mol Sci. 2015:16:14749-68.

82. Yin Z, Li Y, Han X, Shen F. Genome-wide profiling of miRNAs and other small non-coding RNAs in the Verticillium dahliae-inoculated cotton roots. PLoS ONE. 2012;7:e35765.

83. Xin $M$, Wang $Y$, Yao $Y$, Xie $C$, Peng $H, N i$, et al. Diverse set of microRNAs are responsive to powdery mildew infection and heat stress in wheat (Triticum aestivum L.). BMC Plant Biol. 2010;10:123.

84. Chen L, Ren Y, Zhang Y, Xu J, Zhang Z, Wang Y. Genome-wide profiling of novel and conserved Populus microRNAs involved in pathogen stress response by deep sequencing. Planta. 2012;235:873-83.

85. Degliangeli F, Pompa PP, Fiammengo R. Nanotechnology-based strategies for the detection and quantification of microRNA. Chem A Eur J. 2014:20:9476-92.

86. Chen C, Ridzon DA, Broomer AJ, Zhou Z, Lee DH, Nguyen JT, et al. Realtime quantification of microRNAs by stem-loop RT-PCR. Nucleic Acids Res. 2005;33:1-9.

87. LiW, Ruan K. MicroRNA detection by microarray. Anal Bioanal Chem 2009;394:1117-24.

88. Jain PK, ElSayed IH, El-Sayed MA. Au nanoparticles target cancer. Nano Today. 2007;2:18-29.

89. Cai B, Huang L, Zhang H, Sun Z, Zhang Z, Zhang GJ. Gold nanoparticlesdecorated graphene field-effect transistor biosensor for femtomolar MicroRNA detection. Biosens Bioelectron. 2015;74:329-34.

90. Lu Z, Tang H, Wu D, Xia Y, Wu M, Yi X, et al. Amplified voltammetric detection of miRNA from serum samples of glioma patients via combination of conducting magnetic microbeads and ferrocenecapped gold nanoparticle/streptavidin conjugates. Biosens Bioelectron 2016;86:502-7.

91. Wu Y, Huang J, Yang X, Yang Y, Quan K, Xie N, et al. Gold nanoparticle loaded split-DNAzyme probe for amplified miRNA detection in living cells. Anal Chem. 2017;89:8377-83.

92. Su S, Cao W, Liu W, Lu Z, Zhu D, Chao J, et al. Dual-mode electrochemical analysis of microRNA-21 using gold nanoparticle-decorated MoS2 nanosheet. Biosens Bioelectron. 2017;94:552-9.
93. Laurenti M, Paez-Perez M, Algarra M, Alonso-Cristobal P, Lopez-Cabarcos E, Mendez-Gonzalez D, et al. Enhancement of the upconversion emission by visible-to-near-infrared fluorescent graphene quantum dots for miRNA detection. ACS Appl Mater Interfaces. 2016;8:12644-51. https:// doi.org/10.1021/acsami.6b02361.

94. Liu X, Liu L, Xu Q, Wu P, Zuo X, Ji A. MicroRNA as a novel drug target for cancer therapy. Expert Opin Biol Ther. 2012;12:573-80. https://doi.org/1 0.1517/14712598.2012.671293.

95. Bayley $\mathrm{H}$, Jayasinghe L. Functional engineered channels and pores (review). Mol Membr Biol. 2004;21:209-20.

96. Gu L-Q, Shim JW. Single molecule sensing by nanopores and nanopore devices. Analyst. 2010;135:441-51.

97. Hall AR, Scott A, Rotem D, Mehta KK, Bayley H, Dekker C. Hybrid pore formation by directed insertion of a-haemolysin into solid-state nanopores. Nat Nanotechnol. 2010;5:874-7.

98. Movileanu L. Interrogating single proteins through nanopores: challenges and opportunities. Trends Biotechnol. 2009;27:333-41.

99. Olasagasti F, Lieberman KR, Benner S, Cherf GM, Dahl JM, Deamer DW, et al. Replication of individual DNA molecules under electronic control using a protein nanopore. Nat Nanotechnol. 2010;5:798-806.

100. Wang Y, Zheng D, Tan Q, Wang MX, Gu L-Q. Nanopore-based detection of circulating microRNAs in lung cancer patients. Nat Nanotechnol. 2011;6:668-74.

101. Mitchell N, Howorka S. Chemical tags facilitate the sensing of individual DNA strands with nanopores. Angew Chemie Int Ed. 2008;47:5565-8.

102. Singer A, Wanunu M, Morrison W, Kuhn H, Frank-Kamenetskii M, Meller A. Nanopore based sequence specific detection of duplex DNA for genomic profiling. Nano Lett. 2010;10:738-42.

103. Bayley $\mathrm{H}$, Cronin B, Heron A, Holden MA, Hwang WL, Syeda R, et al. Droplet interface bilayers RID B-8725-2008. Mol Biosyst. 2008:4:1191-208.

104. Wanunu M, Dadosh T, Ray V, Jin J, McReynolds L, Drndić M. Rapid electronic detection of probe-specific microRNAs using thin nanopore sensors. Nat Nanotechnol. 2010;5:807-14. https://doi.org/10.1038/ nnano.2010.202.

105. Gu L-Q, Wanunu M, Wang MX, McReynolds L, Wang Y. Detection of miRNAs with a nanopore single-molecule counter. Expert Rev Mol Diagn. 2012:12:573-84.

106. van Rooij E, Kauppinen S. Development of microRNA therapeutics is coming of age. EMBO Mol Med. 2014;6:851-64.

107. Mishra PJ, Merlino G. MicroRNA reexpression as differentiation therapy in cancer. J Clin Invest. 2009;119:2119-23.

108. Rossi JJ. New hope for a MicroRNA therapy for liver cancer. Cell. 2009:137:990-2.

109. Lawrie $\mathrm{CH}$. microRNA expression in lymphoid malignancies: new hope for diagnosis and therapy? J Cell Mol Med. 2008;12:1432-44.

110. Ebert MS, Sharp PA. MicroRNA sponges: progress and possibilities. RNA. 2010:16:2043-50.

111. Crooke ST, Graham MJ, Zuckerman JE, Brooks D, Conklin BS, Cummins $\mathrm{LL}$, et al. Pharmacokinetic properties of several novel oligonucleotide analogs in mice. J Pharmacol Exp Ther. 1996;277:923-37.

112. Yoo BH, Bochkareva E, Bochkarev A, Mou T-C, Gray DM. 2'-O-methylmodified phosphorothioate antisense oligonucleotides have reduced non-specific effects in vitro. Nucleic Acids Res. 2004;32:2008-16.

113. Wahlestedt C, Salmi P, Good L, Kela J, Johnsson T, Hökfelt T, et al. Potent and nontoxic antisense oligonucleotides containing locked nucleic acids. Proc Natl Acad Sci USA. 2000;97:5633-8.

114. Hyrup B, Nielsen PE. Peptide nucleic acids (PNA): synthesis, properties and potential applications. Bioorg Med Chem. 1996;4:5-23.

115. Pallan PS, Greene EM, Jicman PA, Pandey RK, Manoharan M, Rozners E, et al. Unexpected origins of the enhanced pairing affinity of 2 '-fluoromodified RNA. Nucleic Acids Res. 2011;39:3482-95.

116. Braasch DA, Corey DR. Locked nucleic acid (LNA): fine-tuning the recog nition of DNA and RNA. Chem Biol. 2001;8:1-7.

117. Petersen M, Wengel J. LNA: a versatile tool for therapeutics and genomics. Trends Biotechnol. 2003:21:74-81.

118. Campbell MA, Wengel J. Locked vs. unlocked nucleic acids (LNA vs. UNA): contrasting structures work towards common therapeutic goals. Chem Soc Rev. 2011;40:5680. 
119. Guo P, Haque F, Hallahan B, Reif R, Li H. Uniqueness, advantages, challenges, solutions, and perspectives in therapeutics applying RNA nanotechnology. Nucleic Acid Ther. 2012;22:226-45.

120. Reynolds AR, Moein Moghimi S, Hodivala-Dilke K. Nanoparticlemediated gene delivery to tumour neovasculature. Trends Mol Med. 2003;9:2-4.

121. Ravi Kumar M, Hellermann G, Lockey RF, Mohapatra SS. Nanoparticlemediated gene delivery: state of the art. Expert Opin Biol Ther. 2004:4:1213-24.

122. Davies OR, Head L, Armitage D, Pearson EA, Davies MC, Marlow M, et al. Surface modification of microspheres with steric stabilizing and cationic polymers for gene delivery. Langmuir. 2008;24:7138-46.

123. Yuba E, Kojima C, Harada A, Watarai S, Kono K. pH-Sensitive fusogenic polymer-modified liposomes as a carrier of antigenic proteins for activation of cellular immunity. Biomaterials. 2010;31:943-51.

124. Patil YB, Swaminathan SK, Sadhukha T, Ma L, Panyam J. The use of nanoparticle-mediated targeted gene silencing and drug delivery to overcome tumor drug resistance. Biomaterials. 2010;31:358-65.

125. Biju V. Chemical modifications and bioconjugate reactions of nanomaterials for sensing, imaging, drug delivery and therapy. Chem Soc Rev. 2014;43:744-64

126. Riley $M$, Vermerris W. Recent advances in nanomaterials for gene delivery-a review. Nanomaterials. 2017;7:94.

127. Mao S, Sun W, Kissel T. Chitosan-based formulations for delivery of DNA and siRNA. Adv Drug Deliv Rev. 2010;62:12-27.

128. Garcia-Fuentes M, Alonso MJ. Chitosan-based drug nanocarriers: where do we stand? J Control Release. 2012;161:496-504

129. Dai H, Jiang X, Tan GC, Chen Y, Torbenson M, Leong KW, et al. ChitosanDNA nanoparticles delivered by intrabiliary infusion enhance livertargeted gene delivery. Int J Nanomed. 2006;1:507.

130. Roy K, Mao HQ, Huang SK, Leong KW. Oral gene delivery with chitosanDNA nanoparticles generates immunologic protection in a murine model of peanut allergy. Nat Med. 1999:5:387-91.

131. Kumar M, Behera AK, Lockey RF, Zhang J, Bhullar G, De La Cruz CP, et al. Intranasal gene transfer by chitosan-DNA nanospheres protects BALB/C mice against acute respiratory syncytial virus infection. Hum Gene Ther. 2002;13:1415-25.

132. Mckiernan PJ, Greene CM. MicroRNA dysregulation in cystic fibrosis. Mediators Inflamm. 2015;2015:529642.

133. Deng X, Cao M, Zhang J, Hu K, Yin Z, Zhou Z, et al. Hyaluronic acid-chitosan nanoparticles for co-delivery of MiR-34a and doxorubicin in therapy against triple negative breast cancer. Biomaterials. 2014;35:4333-44. https://doi.org/10.1016/j.biomaterials.2014.02.006.

134. Louw AM, Kolar MK, Novikova LN, Kingham PJ, Wiberg M, Kjems J, et al. Chitosan polyplex mediated delivery of miRNA-124 reduces activation of microglial cells in vitro and in rat models of spinal cord injury. Nanomed Nanotechnol Biol Med. 2016;12:643-53.

135. Ewert K, Slack NL, Ahmad A, Evans HM, Lin AJ, Samuel CE, et al. Cationic lipid-DNA complexes for gene therapy: understanding the relationship between complex structure and gene delivery pathways at the molecular level. Curr Med Chem. 2004:11:133-49.

136. Song H, Wang G, He B, Li L, Li C, Lai Y, et al. Cationic lipid-coated PEI/ DNA polyplexes with improved efficiency and reduced cytotoxicity for gene delivery into mesenchymal stem cells. Int J Nanomed. 2012;7:4637-48

137. Anwer K, Meaney C, Kao G, Hussain N, Shelvin R, Earls RM, et al. Cationic lipid-based delivery system for systemic cancer gene therapy. https:// www.nature.com/cgt/journal/v7/n8/pdf/7700218a.pdf. Accessed 26 Sept 2017.

138. Martin B, Sainlos M, Aissaoui A, Oudrhiri N, Hauchecorne M, Vigneron $\mathrm{J}-\mathrm{P}$, et al. The design of cationic lipids for gene delivery. Curr Pharm Des. 2005;11:375-94.

139. Hsu S-H, Yu B, Wang X, Lu Y, Schmidt CR, Lee RJ, et al. Cationic lipid nanoparticles for therapeutic delivery of siRNA and miRNA to murine liver tumor. Nanomedicine. 2013;9:1169-80.

140. Zhang M, Zhou X, Wang B, Yung BC, Lee LJ, Ghoshal K, et al. Lactosylated gramicidin-based lipid nanoparticles (Lac-GLN) for targeted delivery of anti-miR-155 to hepatocellular carcinoma. J Control Release. 2013;168:251-61.

141. Pramanik D, Campbell NR, Karikari C, Chivukula R, Kent OA, Mendell JT, et al. Restitution of tumor suppressor microRNAs using a systemic nanovector inhibits pancreatic cancer growth in mice. Mol Cancer Ther. 2011;10:1470-80.

142. Wu Y, Crawford M, Mao Y, Lee RJ, Davis IC, Elton TS, et al. Therapeutic delivery of microRNA-29b by cationic lipoplexes for lung cancer. Mol Ther Nucleic Acids. 2013;2:e84

143. Piao L, Zhang M, Datta J, Xie X, Su T, Li H, et al. Lipid-based nanoparticle delivery of pre-miR-107 inhibits the tumorigenicity of head and neck squamous cell carcinoma. Mol Ther. 2012;20:1261-9.

144. Liu XQ, Song WJ, Sun TM, Zhang PZ, Wang J. Targeted delivery of antisense inhibitor of miRNA for antiangiogenesis therapy using CRGDfunctionalized nanoparticles. Mol Pharm. 2011:8:250-9.

145. Fernandez-Piñeiro I, Badiola I, Sanchez A. Nanocarriers for microRNA delivery in cancer medicine. Biotechnol Adv. 2017;35:350-60.

146. Oh B, Song H, Lee D, Oh J, Kim G, Ihm S-H, et al. Anti-cancer effect of R3V6 peptide-mediated delivery of an anti-microRNA-21 antisenseoligodeoxynucleotide in a glioblastoma animal model. J Drug Target. 2017;25:132-9. https://doi.org/10.1080/1061186X.2016.1207648.

147. Song H, Oh B, Choi M, Oh J, Lee M. Delivery of anti-microRNA-21 antisense-oligodeoxynucleotide using amphiphilic peptides for glioblastoma gene therapy. J Drug Target. 2015:23:360-70.

148. Suh JS, Lee JY, Choi YS, Chong PC, Park YJ, Park YJ. Peptide-mediated intracellular delivery of miRNA-29b for osteogenic stem cell differentiation. Biomaterials. 2013;34:4347-59.

149. Schnittert J, Kuninty PR, Bystry TF, Brock R, Storm G, Prakash J. AntimicroRNA targeting using peptide-based nanocomplexes to inhibit differentiation of human pancreatic stellate cells. Nanomedicine. 2017;12:1369-84. https://doi.org/10.2217/nnm-2017-0054.

150. Yu Wang K, McCurdy S, Shea RG, Swaminathan S, Bolton PH. A DNA aptamer which binds to and inhibits thrombin exhibits a new structural motif for DNA? Biochemistry. 1993;32:1899-904.

151. Esposito CL, Catuogno S, de Franciscis V, Cerchia L. New insight into clinical development of nucleic acid aptamers. Discov Med. 2011:11:487-96.

152. Dai F, Zhang Y, Zhu X, Shan N, Chen Y. Anticancer role of MUC1 aptamer-miR-29b chimera in epithelial ovarian carcinoma cells through regulation of PTEN methylation. Target Oncol. 2012;7:217-25.

153. Binzel DW, Shu Y, Li H, Sun M, Zhang Q, Shu D, et al. Specific delivery of miRNA for high efficient inhibition of prostate cancer by RNA nanotechnology. Mol Ther. 2016;24:1267-77.

154. Shu D, Li H, Shu Y, Xiong G, Carson WE, Haque F, et al. Systemic delivery of anti-miRNA for suppression of triple Negative breast cancer utilizing RNA nanotechnology. ACS Nano. 2015:9:9731-40.

155. laboni M, Russo V, Fontanella R, Roscigno G, Fiore D, Donnarumma E, et al. Aptamer-miRNA-212 conjugate sensitizes NSCLC cells to TRAIL. Mol Ther Nucleic Acids. 2016;5:e289.

156. Tanno T, Zhang P, Lazarski CA, Liu Y, Zheng P. An aptamer-based targeted delivery of miR-26a protects mice against chemotherapy toxicity while suppressing tumor growth. Blood Adv. 2017;1:1107-19. https:// doi.org/10.1182/bloodadvances.2017004705.

157. Prasad PN. Introduction to biophotonics. Acc Chem Res. 2003. https:// doi.org/10.1002/0471465380.

158. Ghosh R, Singh LC, Shohet JM, Gunaratne PH. A gold nanoparticle platform for the delivery of functional microRNAs into cancer cells. Biomaterials. 2013;34:807-16.

159. Hao L, Patel PC, Alhasan AH, Giljohann DA, Mirkin CA. Nucleic acid-gold nanoparticle conjugates as mimics of microRNA. Small. 2011;7:3158-62.

160. Ekin A, Karatas OF, Culha M, Ozen M. Designing a gold nanoparticlebased nanocarrier for microRNA transfection into the prostate and breast cancer cells. J Gene Med. 2014;16:331-5.

161. Crew E, Rahman S, Razzak-Jaffar A, Mott D, Kamundi M, Yu G, et al. MicroRNA conjugated gold nanoparticles and cell transfection. Anal Chem. 2012:84:26-9.

162. Xue H, Liu Y, Liao J, Lin J, Li B. Gold nanoparticles delivered miR-375 for treatment of hepatocellular carcinoma. Oncotarget. 2016;7:1-12.

163. Kim JH, Yeom JH, Ko JJ, Han MS, Lee K, Na SY, et al. Effective delivery of anti-miRNA DNA oligonucleotides by functionalized gold nanoparticles. J Biotechnol. 2011;155:287-92.

164. Lu CH, Yang HH, Zhu CL, Chen X, Chen GN. A graphene platform for sensing biomolecules. Angew Chemie Int Ed. 2009;48:4785-7.

165. Yang H-W, Huang C-Y, Lin C-W, Liu H-L, Huang C-W, Liao S-S, et al. Gadolinium-functionalized nanographene oxide for combined drug 
and microRNA delivery and magnetic resonance imaging. Biomaterials. 2014;35:6534-42.

166. Murray CB, Kagan CR, Bawendi MG. Synthesis and characterization of monodisperse nanocrystals and close-packed nanocrystal assemblies. Annu Rev Mater Sci. 2000;30:545-610.

167. Kortshagen U. Nonthermal plasma synthesis of semiconductor nanocrystals. J Phys D Appl Phys. 2009. ;42:113001. http://stacks.iop. org/0022-3727/42/i=11/a=113001 key=crossref.1 e802efa4e78c9e6de7 Oab01 b97ed406. Accessed 26 Sept 2017.

168. Liang G, Li Y, Feng W, Wang X, Jing A, Li J, et al. Polyethyleneiminecoated quantum dots for miRNA delivery and its enhanced suppression in HepG2 cells. Int J Nanomed. 2016;11:6079-88.

169. Wang Z, Wu P, He Z, He H, Rong W, Li J, et al. Mesoporous silica nanoparticles with lactose-mediated targeting effect to deliver platinum(iv) prodrug for liver cancer therapy. J Mater Chem. 2017;5:7591-7. http:// xlink.rsc.org/?DOI=C7TB01704A. Accessed 26 Sept 2017.

170. Tivnan A, Orr WS, Gubala V, Nooney R, Williams DE, McDonagh C, et al. Inhibition of neuroblastoma tumor growth by targeted delivery of microRNA-34a using anti-disialoganglioside GD2 coated nanoparticles. PLOS ONE. 2012;7:e38129.

171. Baker A, Saltik M, Lehrmann H, Killisch I, Mautner V, Lamm G, et al. Polyethylenimine (PEI) is a simple, inexpensive and effective reagent for condensing and linking plasmid DNA to adenovirus for gene delivery. Gene Ther. 1997:4:773-82

172. Biray AÇ, Özcan I, Balcı T, Özer Ö, Gündüz C. Design of polyethylene glycol-polyethylenimine nanocomplexes as non-viral carriers: Mir-150 delivery to chronic myeloid leukemia cells. Cell Biol Int. 2013;37:1205-14.

173. Hwang DW, Son S, Jang J, Youn H, Lee S, Lee D, et al. A brain-targeted rabies virus glycoprotein-disulfide linked $P E I$ nanocarrier for delivery of neurogenic microRNA. Biomaterials. 2011;32:4968-75.

174. Ibrahim AF, Weirauch U, Thomas M, Gruñweller A, Hartmann RK, Aigner A. MicroRNA replacement therapy for miR-145 and miR-33a is efficacious in a model of colon carcinoma. Cancer Res. 2011;71:5214-24.

175. Yang YP, Chien Y, Chiou GY, Cherng JY, Wang ML, Lo WL, et al. Inhibition of cancer stem cell-like properties and reduced chemoradioresistance of glioblastoma using microRNA145 with cationic polyurethane-short branch PEI. Biomaterials. 2012;33:1462-76.

176. Liu X, Li G, Su Z, Jiang Z, Chen L, Wang J, et al. Poly(amido amine) is an ideal carrier of miR-7 for enhancing gene silencing effects on the EGFR pathway in U251 glioma cells. Oncol Rep. 2013;29:1387-94. https:// www.spandidos-publications.com/. Accessed 26 Sept 2017.

177. Ren Y, Kang C-S, Yuan X-B, Zhou X, Xu P, Han L, et al. Co-delivery of asmiR-21 and 5-FU by poly(amidoamine) dendrimer attenuates human glioma cell growth in vitro. J Biomater Sci Polym Ed. 2010;21:303-14.

178. Gray WD, Wu RJ, Yin X, Zhou J, Davis ME, Luo Y. Dendrimeric bowties featuring hemispheric-selective decoration of ligands for microRNAbased therapy. Biomacromolecules. 2013;14:101-9.

179. Kulkarni RK, Moore EG, Hegyeli AF, Leonard F. Biodegradable poly(lactic acid) polymers. J Biomed Mater Res. 1971;5:169-81.

180. Blum JS, Saltzman WM. High loading efficiency and tunable release of plasmid DNA encapsulated in submicron particles fabricated from PLGA conjugated with poly-L-lysine. J Control Release. 2008;129:66-72.

181. Ramanlal Chaudhari K, Kumar A, Megraj Khandelwal VK, Ukawala M, Manjappa AS, Mishra AK, et al. Bone metastasis targeting: a novel approach to reach bone using Zoledronate anchored PLGA nanoparticle as carrier system loaded with Docetaxel. J Control Release. 2012;158:470-8

182. Uchegbu IF. Pharmaceutical nanotechnology: polymeric vesicles for drug and gene delivery. Expert Opin Drug Deliv. 2006;3:629-40.

183. Devulapally RS, Narayana MS, Thillai VF, Kira M, Tarik FW, Jürgen K, et al. Polymer nanoparticles mediated codelivery of antimiR-10b and antimiR-21 for achieving triple negative breast cancer therapy. ACS Nano. 2015;9:2290-302.

184. Wang S, Zhang J, Wang Y, Chen M. Hyaluronic acid-coated PEI-PLGA nanoparticles mediated co-delivery of doxorubicin and miR-542-3p for triple negative breast cancer therapy. Nanomed Nanotechnol Biol Med. 2016;12:411-20

185. Bhargava-Shah A, Foygel K, Devulapally R, Paulmurugan R. Orlistat and antisense-miRNA-loaded PLGA-PEG nanoparticles for enhanced triple negative breast cancer therapy. Nanomedicine. 2016;11:235-47.
186. Saraiva C, Paiva J, Santos T, Ferreira L, Bernardino L. MicroRNA-124 loaded nanoparticles enhance brain repair in Parkinson's disease. J Control Release. 2016:235:291-305.

187. Fire A, Xu S, Montgomery MK, Kostas SA, Driver SE, Mello CC. Potent and specific genetic interference by double-stranded RNA in Caenorhabditis elegans. Nature. 1998;391:806-11. https://doi.org/10.1038/35888.

188. Aagaard L, Rossi JJ. RNAi therapeutics: principles, prospects and challenges. Adv Drug Deliv Rev. 2007;59:75-86.

189. Ni JZ, Chen E, Gu SG. Complex coding of endogenous siRNA, transcriptional silencing and H3K9 methylation on native targets of germline nuclear RNAi in C. elegans. BMC Genomics. 2014;15:1157.

190. Obad S, dos Santos CO, Petri A, Heidenblad M, Broom O, Ruse C, et al. Silencing of microRNA families by seed-targeting tiny LNAs. Nat Genet. 2011:43:371-8

191. Alvarez JP, Pekker I, Goldshmidt A, Blum E, Amsellem Z, Eshed Y. Endogenous and synthetic microRNAs stimulate simultaneous, efficient, and localized regulation of multiple targets in diverse species. Plant Cell. 2006;18:1134-51.

192. Parizotto EA, Dunoyer P, Rahm N, Himber C, Voinnet O. In vivo investigation of the transcription, processing, endonucleolytic activity, and functional relevance of the spatial distribution of a plant miRNA. Genes Dev. 2004:18:2237-42.

193. Schwab R, Ossowski S, Riester M, Warthmann N, Weigel D. Highly specific gene silencing by artificial microRNAs in Arabidopsis. Plant Cell Online. 2006;18:1121-33.

194. Zeng Y, Wagner EJ, Cullen BR. Both natural and designed micro RNAs can inhibit the expression of cognate mRNAs when expressed in human cells. Mol Cell. 2002;9:1327-33.

195. Ai T, Zhang L, Gao Z, Zhu CX, Guo X. Highly efficient virus resistance mediated by artificial microRNAs that target the suppressor of PVX and PVY in plants. Plant Biol. 2011;13:304-16.

196. Qu J, Ye J, Fang R. Artificial microRNAs for plant virus resistance. Methods Mol Biol. 2012:894:209-22.

197. Niu Q-W, Lin S-S, Reyes JL, Chen K-C, Wu H-W, Yeh S-D, et al. Expression of artificial microRNAs in transgenic Arabidopsis thaliana confers virus resistance. Nat Biotechnol. 2006;24:1420-8.

198. Duan C-G, Wang C-H, Fang R-X, Guo H-S. Artificial microRNAs highly accessible to targets confer efficient virus resistance in plants. J Virol. 2008;82:11084-95.

199. Fahim M, Millar AA, Wood CC, Larkin PJ. Resistance to Wheat streak mosaic virus generated by expression of an artificial polycistronic microRNA in wheat. Plant Biotechnol J. 2012;10:150-63.

200. Kung YJ, Lin SS, Huang YL, Chen TC, Harish SS, Chua NH, et al. Multiple artificial microRNAs targeting conserved motifs of the replicase gene confer robust transgenic resistance to negative-sense single-stranded RNA plant virus. Mol Plant Pathol. 2012;13:303-17.

201. Qu J, Ye J, Fang R. Artificial microRNA-mediated virus resistance in plants. J Virol. 2007:81:6690-9.

202. Wagaba H, Patil BL, Mukasa S, Alicai T, Fauquet CM, Taylor NJ. Artificial microRNA-derived resistance to Cassava brown streak disease. J Virol Methods. 2016:231:38-43.

203. Simón-Mateo C, García JA. MicroRNA-guided processing impairs Plum pox virus replication, but the virus readily evolves to escape this silencing mechanism. J Virol. 2006;80:2429-36.

204. Jelly NS, Schellenbaum P, Walter B, Maillot P. Transient expression of artificial microRNAs targeting Grapevine fanleaf virus and evidence for RNA silencing in grapevine somatic embryos. Transgenic Res. 2012;21:131927. https://doi.org/10.1007/s11248-012-9611-5.

205. Zhang X, Li H, Zhang J, Zhang C, Gong P, Ziaf K, et al. Expression of artificial microRNAs in tomato confers efficient and stable virus resistance in a cell-autonomous manner. Transgenic Res. 2011;20:569-81.

206. Ali I, Amin I, Briddon RW, Mansoor S. Artificial microRNA-mediated resistance against the monopartite begomovirus cotton leaf curl Burewala virus. Virol J. 2013;10:231

207. Van VuT, Roy Choudhury N, Mukherjee SK. Transgenic tomato plants expressing artificial microRNAs for silencing the pre-coat and coat proteins of a begomovirus, tomato leaf curl New Delhi virus, show tolerance to virus infection. Virus Res. 2013;172:35-45.

208. Lin S-S, Wu H-W, Elena SF, Chen K-C, Niu Q-W, Yeh S-D, et al. Molecular evolution of a viral non-coding sequence under the selective pressure 
of amiRNA-mediated silencing. PLoS Pathog. 2009;5:e1000312. https:// doi.org/10.1371/journal.ppat.1000312.

209. Sun L, Lin C, Du J, Song Y, Jiang M, Liu H, et al. Dimeric artificial microRNAs mediate high resistance to RSV and RBSDV in transgenic rice plants. Plant Cell Tissue Organ Cult. 2016;126:127-39. https://doi. org/10.1007/s11240-016-0983-8.

210. Kis A, Tholt G, Ivanics M, Várallyay É, Jenes B, Havelda Z. Polycistronic artificial miRNA-mediated resistance to Wheat dwarf virus in barley is highly efficient at low temperature. Mol Plant Pathol. 2016;17:427-37.

211. Mitter N, Zhai Y, Bai AX, Chua K, Eid S, Constantin M, et al. Evaluation and identification of candidate genes for artificial microRNA-mediated resistance to tomato spotted wilt virus. Virus Res. 2016;211:151-8.

212. Zuker M. Mfold web server for nucleic acid folding and hybridization prediction. Nucleic Acids Res. 2003;31:3406-15.

213. Markham NR, Zuker M. UNAFold. Methods Mol Biol. 2008;453:3-31.

214. Bindewald E, Grunewald C, Boyle B, O'Connor M, Shapiro BA. Computational strategies for the automated design of RNA nanoscale structures from building blocks using nanotiler. J Mol Graph Model. 2008;27:299-308.

215. Yingling YG, Shapiro BA. Computational design of an RNA hexagonal nanoring and an RNA nanotube. Nano Lett. 2017;7:2328-34. https://doi. org/10.1021/nl070984r.

216. Afonin KA, Bindewald E, Yaghoubian AJ, Voss N, Jacovetty E, Shapiro BA, et al. In vitro assembly of cubic RNA-based scaffolds designed in silico. Nat Nanotechnol. 2010;5:676-82.

217. Watts J, Deleavey G, Damha M. Chemically modified siRNA: tools and applications. Drug Discov Today. 2008;13:842-55.

218. Singh Y, Murat P, Defrancq E. Recent developments in oligonucleotide conjugation. Chem Soc Rev. 2010;39:2054.

219. Mathé C, Périgaud C. Recent approaches in the synthesis of conformationally restricted nucleoside analogues. Eur J Org Chem. 2008;2008:1489-505. https://doi.org/10.1002/ejoc.200700946.

220. Patra A, Richert C. High fidelity base pairing at the $3^{\prime}$-terminus. J Am Chem Soc. 2009;131:12671-81. https://doi.org/10.1021/ja9033654.
221. Liu J, Guo S, Cinier M, Shlyakhtenko LS, Shu Y, Chen C, et al. Fabrication of stable and RNase-resistant RNA nanoparticles active in gearing the nanomotors for viral DNA packaging. ACS Nano. 2011;5:237-46. https:// doi.org/10.1021/nn1024658.

222. Prabha S, Zhou W-Z, Panyam J, Labhasetwar V. Size-dependency of nanoparticle-mediated gene transfection: studies with fractionated nanoparticles. Int J Pharm. 2002;244:105-15.

223. Abdelmawla S, Guo S, Zhang L, Pulukuri SM, Patankar P, Conley P, et al. Pharmacological characterization of chemically synthesized monomeric phi29 pRNA nanoparticles for systemic delivery. Mol Ther. 2011;19:1312-22.

224. Sharma A, Haque F, Pi F, Shlyakhtenko LS, Evers BM, Guo P. Controllable self-assembly of RNA dendrimers. Nanomedicine. 2016;12:835-44.

225. Wang D, Zhang Z, O'Loughlin E, Lee T, Houel S, O'Carroll D, et al. Quantitative functions of Argonaute proteins in mammalian development. Genes Dev. 2012;26:693-704.

226. Moore CB, Guthrie EH, Huang MT, Taxman DJ. RNA therapeutics. Methods. 2010;629:141-58.

227. Jasinski DL, Schwartz CT, Haque F, Guo P. Large ccale purification of RNA nanoparticles by preparative ultracentrifugation. Methods Mol Biol. 2015;1297:67-82.

228. Guo S, Tschammer N, Mohammed S, Guo P. Specific delivery of therapeutic RNAs to cancer cells via the dimerization mechanism of phi29 motor pRNA. Hum Gene Ther. 2005;16:1097-110.

229. Cui D, Zhang C, Liu B, Shu Y, Du T, Shu D, et al. Regression of gastric cancer by systemic injection of RNA nanoparticles carrying both ligand and siRNA. Sci Rep. 2015;5:10726.

230. Kwon YJ. Before and after endosomal escape: roles of stimuli-converting siRNA/polymer interactions in determining gene silencing efficiency. Acc Chem Res. 2012;45:1077-88. https://doi.org/10.1021/ ar200241v.
Ready to submit your research? Choose BMC and benefit from:

- fast, convenient online submission

- thorough peer review by experienced researchers in your field

- rapid publication on acceptance

- support for research data, including large and complex data types

- gold Open Access which fosters wider collaboration and increased citations

- maximum visibility for your research: over 100M website views per year

At BMC, research is always in progress.

Learn more biomedcentral.com/submissions 